\title{
WestVirginiaUniversity
}

THE RESEARCH REPOSITORY @ WVU

Graduate Theses, Dissertations, and Problem Reports

2009

\section{Age differences in younger and older adults' experience of interpersonal problems}

Leo Schlosnagle

West Virginia University

Follow this and additional works at: https://researchrepository.wvu.edu/etd

\section{Recommended Citation}

Schlosnagle, Leo, "Age differences in younger and older adults' experience of interpersonal problems" (2009). Graduate Theses, Dissertations, and Problem Reports. 4527.

https://researchrepository.wvu.edu/etd/4527

This Thesis is protected by copyright and/or related rights. It has been brought to you by the The Research Repository @ WVU with permission from the rights-holder(s). You are free to use this Thesis in any way that is permitted by the copyright and related rights legislation that applies to your use. For other uses you must obtain permission from the rights-holder(s) directly, unless additional rights are indicated by a Creative Commons license in the record and/ or on the work itself. This Thesis has been accepted for inclusion in WVU Graduate Theses, Dissertations, and Problem Reports collection by an authorized administrator of The Research Repository @ WVU. For more information, please contact researchrepository@mail.wvu.edu. 
Age Differences in Younger and Older Adults' Experience of Interpersonal Problems

Leo Schlosnagle, B.A.

Thesis submitted to the Eberly College of Arts and Sciences

at West Virginia University

in partial fulfillment of the requirements

for the degree of

\title{
Master of Science
}

in

Psychology

\author{
JoNell Strough, Ph.D., Chair \\ Amy Fiske, Ph.D. \\ Amy Gentzler, Ph.D.
}

\author{
Department of Psychology \\ Morgantown, West Virginia \\ 2009
}

Keywords: adulthood, age differences, interpersonal problem solving 


\section{ABSTRACT \\ Age Differences in Younger and Older Adults' \\ Experience of Interpersonal Problems}

\section{Leo Schlosnagle}

Differences between younger $(N=78)$ and older $(N=78)$ adults' frequency of experience of interpersonal problems were examined. Previous research has shown agerelated declines in contact frequency and negative interactions (Akiyama, et al., 2003; Carstensen, 1992). Aging has also been associated with concurrent increases in emotional closeness and relationship satisfaction with social partners (Birditt, et al., 2005; Lang \& Carstensen, 2002), and social self-efficacy and problem-solving effectiveness (Artistico, Cervone, and Pezzuti, 2003; Blanchard-Fields, Mienaltowski, \& Seay, 2007; Lachman, 1986). In the current study, older adults reported experiencing interpersonal problems significantly less often than younger adults. Older adults also reported less contact frequency with social partners, more self-efficacy, more positive relationship quality, and a lower degree of negative relationship quality than younger adults. Contact frequency and negative relationship quality both predicted frequency of experience of interpersonal problems. Among the contact frequency, self-efficacy, positive and negative relationship quality variables, none mediated an observed inverse relation between age and interpersonal problem frequency. Limitations and implications of the current study, as well as directions of future research are discussed. 


\section{TABLE OF CONTENTS}

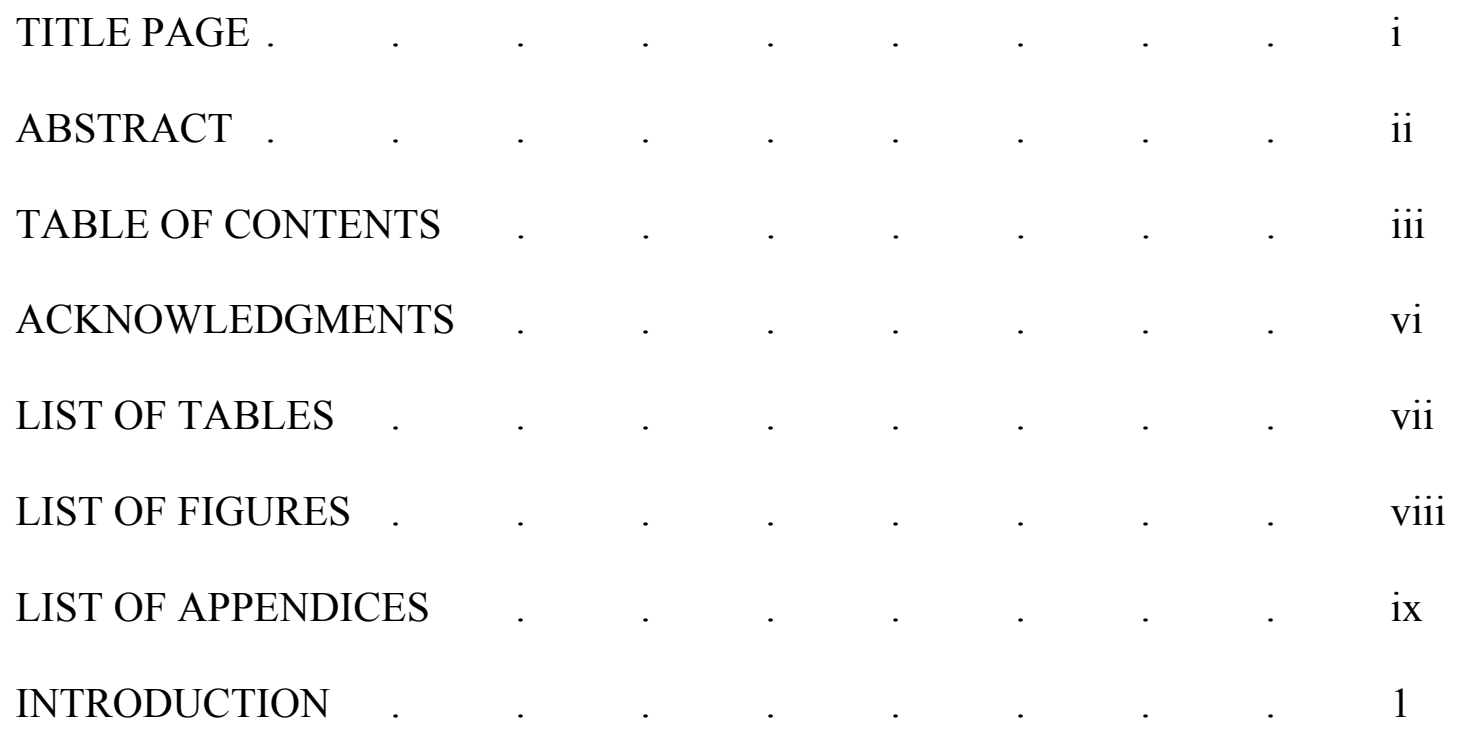

Age Differences in the Experience of Interpersonal Problems . 2

Potential Explanations for Age Differences in Frequency of Interpersonal

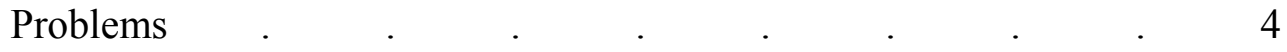

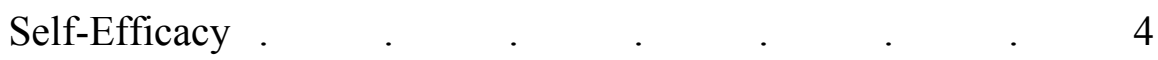

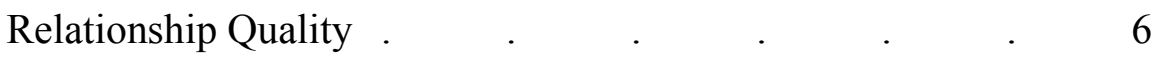

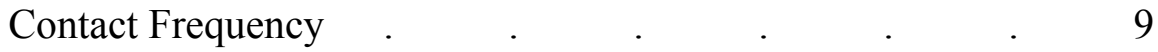

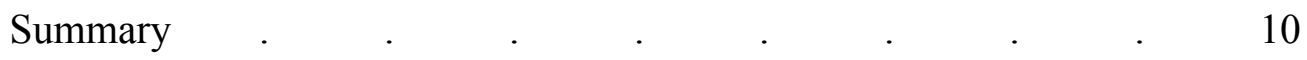

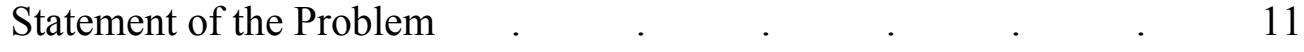

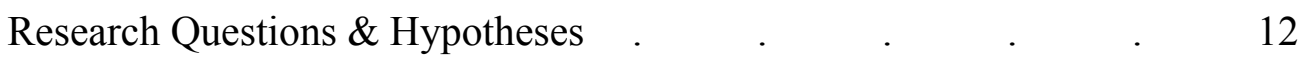

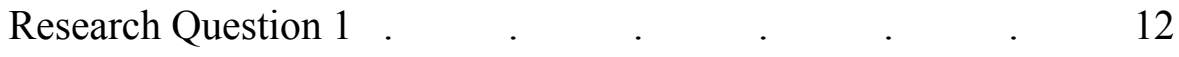

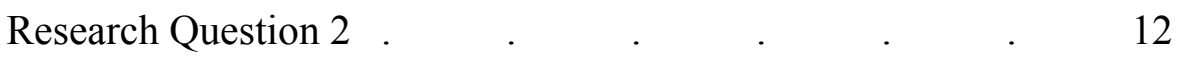

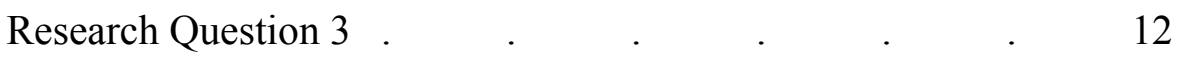

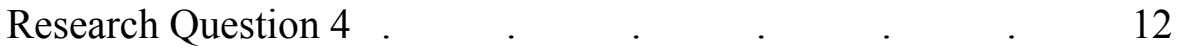




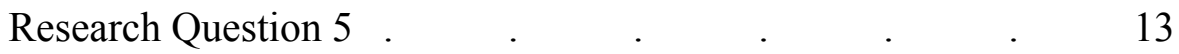

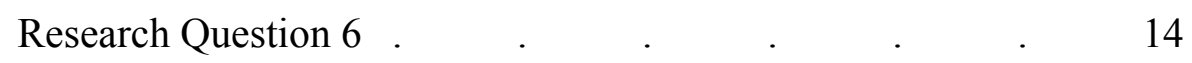

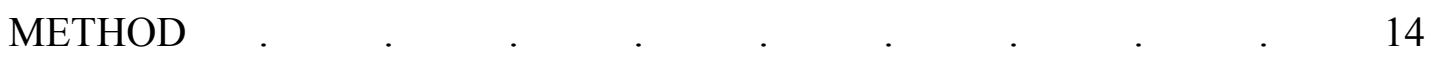

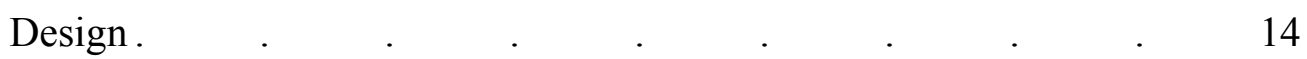

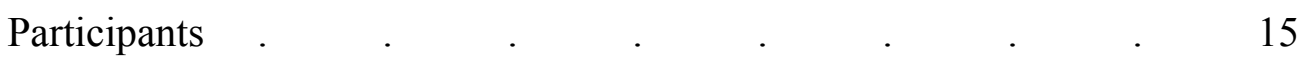

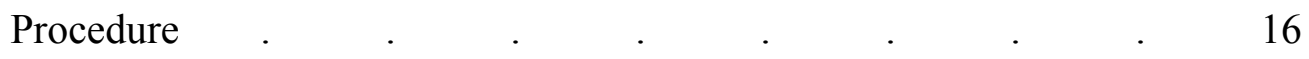

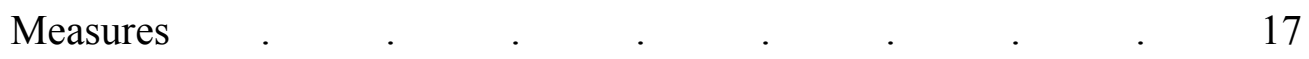

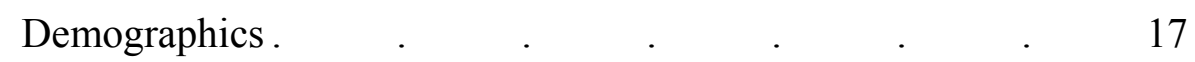

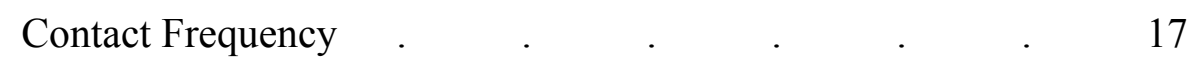

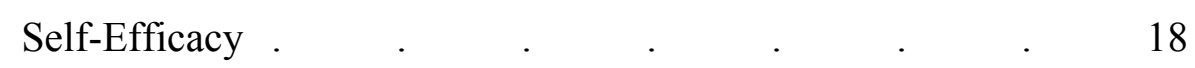

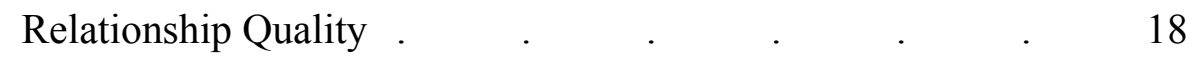

Frequency of Interpersonal Everyday Problems . . 19

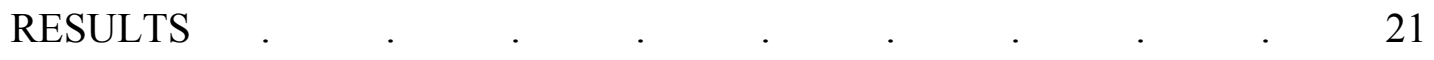

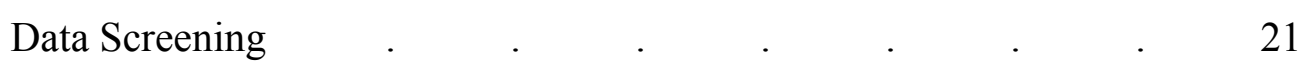

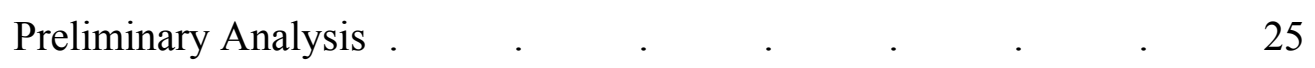

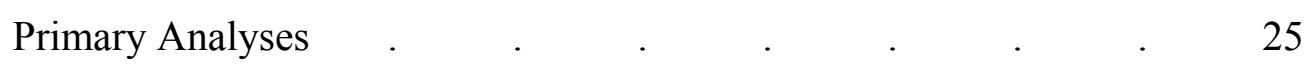

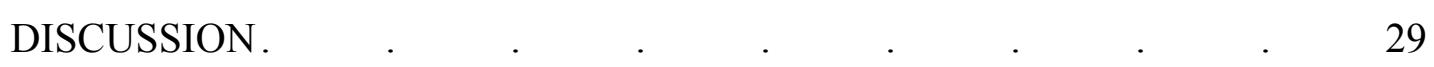

Age Differences in Frequency of Experience of Interpersonal

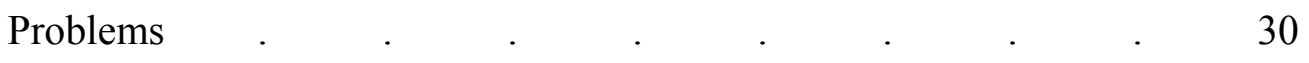

Gender Differences in the Frequency of Experience of Interpersonal

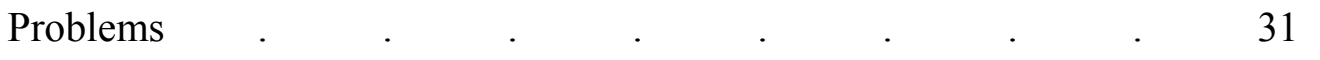

Age Differences in Contact Frequency and Positive Relationship

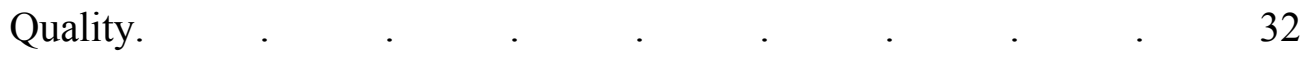




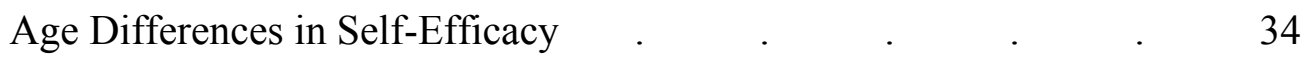

Age Differences in Negative Relationship Quality . . . . 35

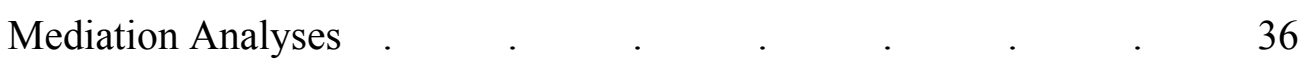

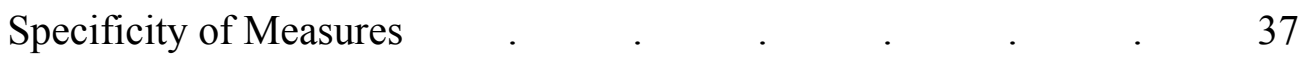

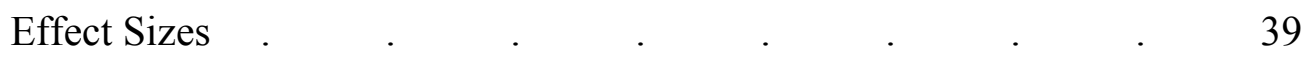

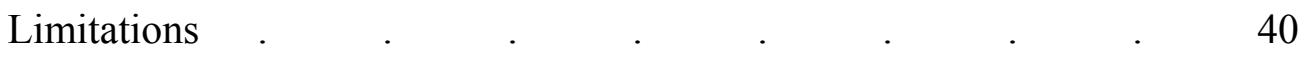

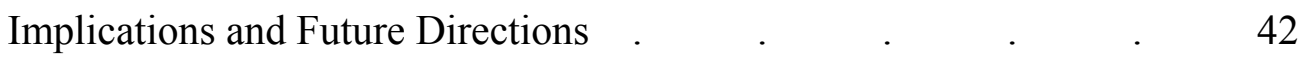

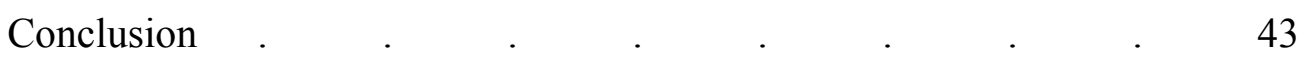

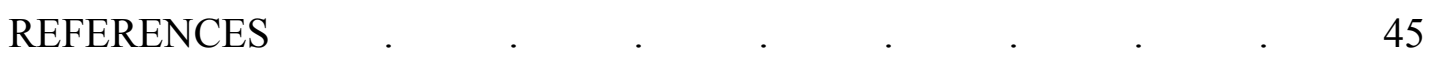

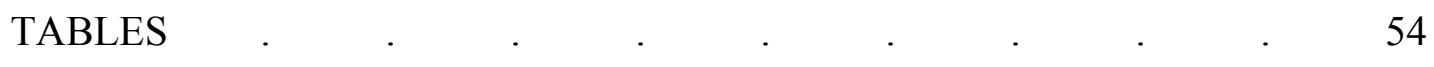

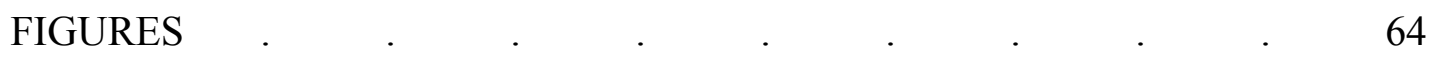

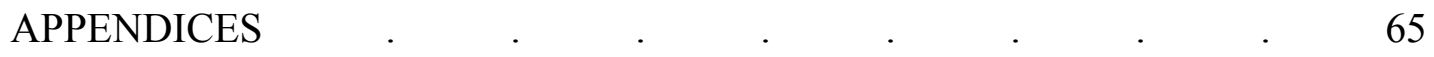




\section{ACKNOWLEDGEMENTS}

I would like to acknowledge my thesis committee; Dr. JoNell Strough (Chair), Dr. Amy Gentzler, and Dr. Amy Fiske for their help and assistance that has been invaluable in helping make this project a success. Additionally, I would like to thank my adviser, Dr. JoNell Strough for her close and helpful supervision over the past two years. Lastly, I would like to thank all of my previous mentors and instructors to whom I am forever appreciative. 


\section{LIST OF TABLES}

1. Multivariate and Univariate Analysis of Variance of the Effect of Age Group on Contact Frequency, Self- Efficacy, Positive, andNegative Relationship Quality . . . . . 60

2. Mean Scores and Standard Deviations for Measures of Contact Frequency, Self-Efficacy, Positive, and Negative Relationship Quality for as a Function of Age Group. .

3. Correlation Coefficients for Relations Among Contact Frequency, Self-Efficacy, Positive, and Negative Relationship Quality, and Average Interpersonal Problem Frequency.

4. Hierarchical Regression for Variables Predicting Average Interpersonal Problem Frequency. .

5. Contact Frequency as a Mediator of the Relation Between Age Group and Average Interpersonal Problem Frequency

6. Self-Efficacy as a Mediator of the Relation Between

Age Group and Average Interpersonal Problem Frequency .

7. Positive Relationship Quality as a Mediator of the Relation Between Age Group and Average Interpersonal Problem Frequency . .

8. Negative Relationship Quality as a Mediator of the Relation Between Age Group and Average Interpersonal Problem Frequency .

9. Significance of Indirect Effect of Age Group on Interpersonal Problem Frequency Through Each Potential Mediator (Sobel Test)

10. Intraclass Correlation Coefficients Between All Variables . . 22 


\section{LIST OF FIGURES}

1. Average interpersonal problem frequency score among younger and older adults 


\section{LIST OF APPENDICES}

APPENDIX A: Demographics Questionnaire

APPENDIX B: Attitudes About Relationship Questionnaire. $\quad$. $\quad$. 44

APPENDIX C: Self-Efficacy Scale . $\quad . \quad$. $\quad . \quad$. $\quad . \quad$. $\quad$. 44

APPENDIX D: Your Experience with Everyday Problems. . $\quad$. $\quad$. 44 


\section{Introduction}

Individuals' social networks - the groups of people including friends, acquaintances, and family members with whom individuals interact—change as they age. Specifically, social networks change with age in quantity, or the number of individuals involved in one's social network (Carstensen, 1992). Additionally, individuals' interactions with members of their social networks change both in frequency of occurrence, and in quality, or the types of interactions one has with social partners (Akiyama, Akiyama, Antonucci, Takahashi, \& Langfahl, 2003; Birditt, Fingerman, \& Almeida, 2005; Carstensen, 1992; Lang \& Carstensen, 2002). With specific regard to the quality of social interactions, interpersonal problems - situations in which an individual is dealing with a problem in a relationship (Berg, Strough, Calderone, Sansone, \& Weir, 1998; Blanchard-Fields et al., 2007), such as an argument (Birditt et al., 2005)— generally become less common and less salient with age. However, interactions with close social partners who provide high levels of support become more frequent, satisfying and emotionally close (Akiyama, et al., 2003; Birditt, et al., 2005; Carstensen, 1992).

Although the occurrence of interpersonal problems appears be related to age, sex has been a less consistent predictor of interpersonal problems - with some research suggesting that females report more negative social interactions (Crick \& Grotpeter, 1995; Pagel, Erdly, \& Becker, 1987), and other research failing to uncover any gender differences (Krause \& Shaw, 2002; Stephens, Kinney, Norris, \& Ritchie, 1987). However, research has shown gender differences in reactions to interpersonal elements of everyday problems and interpersonal problems themselves. Specifically, women tend to be more likely to emphasize interpersonal aspects of everyday problems (Strough, Berg, 
\& Sansone, 1996) and tend to report greater and longer-lasting distress related to interpersonal problems (Birditt \& Fingerman, 2003) compared to men. Similarly, when considering their own moral conflicts, women have been shown to be more likely than men to report conflicts occurring within personal relationships (Walker, de Vries, \& Trevethan, 1987).

Despite a reduced frequency of interpersonal problems in older adulthood, interpersonal problems are associated with several negative outcomes among older adults (Finch \& Zautra, 1992; Pagel et al, 1987; Rook, 1984). Thus, it is relevant to understand the mechanisms underlying the occurrence of interpersonal problems. The first goal of the current study is to examine whether there are age and gender differences in the frequency of experience of several specific kinds of interpersonal problems. The second goal of the current study is to assess four predictor variables - contact frequency, perceived self-efficacy, positive, and negative relationship quality — each of which may explain age and/ or gender differences in the frequency of interpersonal problems.

\section{Age Differences in the Experience of Interpersonal Problems}

Existing research on age differences in interpersonal problem frequency has primarily relied on interviews as a means of data collection. Using structured interviews, Akiyama and colleagues (2003) asked participants to indicate their degree of agreement with statements regarding positive and negative interactions with their parents, spouse, child, and same-sex best friend. Participants rated their agreement with each statement on a 5-point scale. Akiyama and colleagues found age differences in the frequency of negative interactions, with older adults reporting that they experienced fewer negative interactions than younger adults. 
Similarly, Birditt, and colleagues (2005) employed archival data from daily phone interviews which were conducted over the course of 8 days. The interviews included stem questions designed to elicit open-ended descriptions of interpersonal problems. Similar to Akiyama and colleagues (2003), Birditt and colleagues found older adults reported experiencing fewer interpersonal problems than younger adults.

Carstensen (1992) also utilized data from archival interviews to examine age changes in emotional closeness with social partners and interpersonal contact frequency. The archival interviews consisted of both structured and open-ended segments, and were conducted longitudinally over a period of 34 years with participants being re-interviewed at four different time points. Interview transcripts were then coded and rated on contact frequency, emotional closeness, and relationship satisfaction. Findings indicated intraindividual age decreases in contact frequency with acquaintances and close friends, but also intraindividual age increases in emotional closeness with close friends between younger and older adulthood.

As evidenced by the literature discussed here, much of the previous research related to age differences in interpersonal problem frequency has utilized interviews (Birditt, et al., 2005). This approach has allowed participants to describe interpersonal problems in either a relatively open-ended or indirect manner. A limitation of this approach is the fact that different age groups and different individuals within age groups may vary in how they interpret open-ended questions regarding interpersonal problems, and subsequently may vary in their responses (Schwartz, 1999). Indeed, some individuals may be less willing to disclose their experience with certain kinds of interpersonal problems than others. Furthermore, some previous studies (Akiyama, et al., 
2003) have assessed the occurrence of interpersonal problems indirectly, and have not required participants to explicitly state which specific kinds of interpersonal problems they have experienced.

The current study, however, examined age differences in the frequency of experience of several explicitly described and specific kinds of interpersonal problems involving non-family social partners. The advantage of this approach is that all participants provided data regarding the frequency at which they experienced interpersonal problems. Moreover, more specific conclusions can be drawn regarding the types of interpersonal problems younger and older adults experience.

\section{Potential Explanations for Age Differences in Frequency of Interpersonal}

\section{Problems}

\section{Self-Efficacy}

Bandura (1986) notes that individuals' behaviors (including social behaviors) are regulated in part through their self-efficacy — their beliefs in how adept they are at performing a given task, such as solving an interpersonal problem. Self-efficacy beliefs have been positively related with the amount of effort expended to complete a given task (Bandura, Adams, \& Beyer, 1977), performance motivation (Bandura \& Cervone, 1983), and negatively related to stress regarding cognitive tasks (Bandura, Cioffi, Taylor, \& Brouillard, 1988). Moreover, self-efficacy has also been shown to be inversely related to anticipatory and performance distress while coping with environmental threats (Bandura, Reese, \& Adams, 1982). In terms of interpersonal interactions, self-efficacy has been noted to be positively related to performance on social tasks (Christie \& Segrin, 1998), and negatively related to self-rated shyness (Caprara, Steca, Cervone, \& Artistico, 2003), 
interpersonal communication apprehension (Hopf \& Colby, 1992), and to social stress (Matsushima \& Shiomi, 2003). Therefore, it appears that self-efficacy may be associated with how individuals interact socially, and solve interpersonal problems.

With regard to age differences in self-efficacy, optimization - a "...hallmark of any traditional conception of development.” (Baltes, 1997, p. 371)—suggests a developmental progression toward an increasingly adaptive use of previously acquired knowledge and skills, albeit in the context of selection and compensation processes that occur with age. More specifically, Sansone and Berg (1993) note that individuals' perceptions of their own abilities — their self-efficacy — may change with age. Previous research has yielded inconsistent findings, with some literature suggesting that selfefficacy declines with age, and other literature suggesting that it remains stable or increases into older adulthood (Lachman, 1986). However, Baltes notes that expertise with, and knowledge of, a given domain often increase with age — an aspect of aging that Lachman echoes by noting findings suggesting that personal self-efficacy does increase during late adulthood.

Moreover, these changes in self-efficacy may relate to how individuals define or interpret problems, and how they cope with them. Artistico, Cervone, and Pezzuti (2003) note that older adults report greater perceived self-efficacy when problems - such as interpersonal problems - are relevant to their age group, and are subsequently able to produce more solutions for such problems than younger adults. Indeed, despite sometimes being at a disadvantage to younger adults in problem-solving contexts, older adults have been shown to be capable of out-performing younger adults on social problem solving tasks when working with a social partner, particularly when those tasks 
are ecologically relevant and dependent on expertise or wisdom-variables which may increase with age (Baltes, 1997; Staudinger \& Baltes, 1996).

If older adults have a high level of self-efficacy regarding interpersonal problemsolving, they may be able to generate more effective strategies to prevent and solve such problems. This, in turn, may be associated with decreases in the frequency of interpersonal problems during older adulthood. For example, older adults have been observed to select effective problem-solving strategies more often than younger adults when considering interpersonal problems (Blanchard-Fields, Mienaltowski, \& Seay, 2007). Specifically, older adults tend to favor avoidant-denial problem-solving strategies - the type of strategies that would likely distance an individual from involvement in the problem, thereby reducing the opportunity for continued conflict (Blanchard-Fields, Jahnke, \& Camp, 1995; Blanchard-Fields, et al., 2007). The current study examined whether perceived self-efficacy regarding everyday problem-solving ability was negatively related to interpersonal problem frequency, and whether it mediated a negative relation between age and interpersonal problem frequency.

\section{Relationship Quality}

Relationship quality appears to be encompassed by two general domainspositive relationship quality, characterized by frequent occurrence of prosocial behaviors, and negative quality, typified by conflict (Berndt, 2002; Blieszner \& Adams, 1998; Hartup, 1996; Oswald, Clark, \& Kelly, 2004). Both positive and negative qualities can lead to a variety of outcomes (Blieszner \& Adams, 1998; Horowitz, Reinhardt, Boerner, \& Travis, 2003), and although the implications of relationship quality between same-sex friends in adulthood is not as well understood as it is between children, adolescents, and 
spouses, friendship quality may be more important to developmental outcomes than the occurrence of friendship itself (Hartup \& Stevens, 1997).

Although social relationships change across the life span, they provide resources at each point of development through both surface and a the deep structure of the relationship - with surface structure consisting of the social exchanges that are typical of the relationship, and deep structure referring to the social meaning or significance of the relationship (Hartup \& Stevens, 1997). Indeed, the surface structure of a relationship consists of "...the actual exchanges that occur between friends—-[and] differ from situation to situation and from early childhood to old age." (Hartup \& Stevens, 1997, p. 356). For instance, Akiyama and colleagues (2003) observed a general reduction in individuals' reports of negative social interactions (an example of a negative relationship quality) across several age groups ranging from 20 years old to over 75 years old, with the exception of negative social interactions between Japanese spouses - which was not significantly different between age groups.

The deep structure of friendships is defined in part by the occurrence of "symmetrical reciprocity"; the mutual exchange of resources within a dyadic relationship that facilitate positive relationship quality, coping, and subsequently, positive developmental outcomes (Hartup \& Stevens, 1997). For example, older adults who have high perceived equity between themselves and a friend report greater friendship satisfaction with that individual than individuals who report feeling either over-benefited or under-benefited (Roberto \& Scott, 1986). Indeed, both younger and older adults place an approximately equal amount of importance on such mutual exchanges when describing ideal relationships (Hartup \& Stevens, 1997). 
Of interest to the current study is whether age differences in the frequency of interpersonal problems may be related to age differences in relationship quality. Although interaction frequency with some social partners decreases, positive deep structure relationship qualities, such as emotional closeness and relationship satisfaction with close friends and family members, tend to increase with age (Carstensen, 1992). Moreover, older adults consider anticipated affect to be more important than younger adults when appraising potential social partners, and prefer interacting with familiar social partners more often than younger adults (Fredrickson \& Carstensn, 1990). Thus, older adults are likely to seek out more familiar social partners that are anticipated to foster positive affect - thereby limiting the opportunity for interpersonal problems to arise. Indeed, as individuals age, their social networks generally decrease in quantity, and their social interactions increase in quality, especially with familiar social partners (Carstensen, Isaacowitz, \& Charles,1999; Carstensen, 1992; Fredrickson \& Carstensen, 1990). This trend appears to continue even into very old age. When comparing old adults to very old adults, both age groups have approximately the same number of close friends within their social networks, despite the fact that the total size of the very old adults' social networks is approximately half as large as those of old adults (Lang \& Carstensen, 1994). Thus, as individuals age, they tend to reduce their social networks in size primarily by reducing the number of casual acquaintances while maintaining close relationships with friends and family (Carstensen, 1992; Lang \& Carstensen, 1994).

Considering that social interactions in older adulthood tend to occur with fewer casual acquaintances, and more social partners who are emotionally close, familiar, highly supportive, and selected based on anticipated affect, it appears that positive 
relationship qualities are maximized in older adulthood. Therefore, opportunities for interpersonal conflicts may become less common with age, and thus interpersonal problems may decrease in frequency as individuals age. Thus, the current study examined whether positive relationship quality was inversely related to the frequency of interpersonal problems, and whether negative relationship quality was positively related to the frequency of interpersonal problems. Moreover, the current study also assessed whether positive and negative relationship quality served as mediators of an inverse relation between age and interpersonal problem frequency.

\section{Contact Frequency}

Carstensen (1992) proposed a model—Socioemotional Selectivity Theory—to explain the change in social network structure and social partner contact frequency that often occurs between early and later adulthood. Socioemotional Selectivity Theory is grounded in empirical evidence that shows that between younger adulthood and older adulthood, the frequency of interactions individuals experience with some social partners decreases, and sometimes stops all together (Carstensen, 1992; Lang \& Carstensen, 1994). For example, contact frequency with acquaintances and close friends become less common however, interactions with spouses and siblings become more common with age (Carstensen, 1992). Similar patterns occur well into very old age; very old adults have social networks approximately half of the size of old adults, which presumably limits their contact frequency to a relatively small number of individuals (Lang \& Carstensen, 1994). 
In addition to age differences, there may also be gender differences in contact frequency. Previous research has found that women spend more time with social partners than men (Wong \& Csikszentmihalyi, 1991)

These age and gender differences in contact frequency may be related to age differences in the frequency of interpersonal problems. Indeed, Akiyama and colleagues (2003) examined three explanatory variables: social maturity (e.g. the ability to recognize the needs of others), familiarity (i.e. the duration of the social relationship), and contact frequency (ranging from no contact to once a day or more) in their study of age differences in interpersonal problem frequency. Among these three, contact frequency best explained age reductions in negative social interactions - individuals who interacted with others at a lower frequency also experienced negative social interactions at a lower frequency. In the current study, contact frequency was studied in order to determine whether contact frequency and frequency of interpersonal problems were positively related. Moreover, based on the previous research conducted by Akiyama and colleagues, contact frequency was expected to account for a greater degree of variance in interpersonal problem frequency than the other predictor variables. Additionally, contact frequency was assessed as a potential mediator of an inverse relation between age and interpersonal problem frequency.

\section{Summary}

Given the existing theoretical framework regarding age differences in social networks and social interactions, and the corresponding literature supporting such theories, it would be reasonable to expect that older adults' social interactions are quantitatively and qualitatively different than those of younger adults. The current study 
was intended to add to the knowledge of whether age differences in the frequency of interpersonal problems exist, and if so, which factors best explain such age differences. Specifically, the current study assessed four explanatory variables — contact frequency, perceived self-efficacy, positive and negative relationship quality — to see which best predicts frequency of experience of interpersonal problems, and which mediates age differences in frequency of experience of said interpersonal problems.

\section{Statement of the Problem}

Individuals' social networks change with age in terms of both the quantity and quality of interactions. Contact with social partners generally declines, and emotional closeness with social partners generally increases with age (Carstensen, 1992; Lang \& Carstensen, 2002). Additionally, negative interactions generally become less common with age (Akiyama, et al., 2003; Birditt, et al., 2005). However, although negative interactions may be less common and less salient in older adulthood, (Birditt, et al.) the correlates of negative interactions — such as increasing the risk of depression — appear to remain relevant to older adults (Finch \& Zautra, 1992). Moreover, some research has shown gender differences in how often individuals report interpersonal problems, with women generally emphasizing and reporting such problems more often than men (Birditt \& Fingerman, 2003; Crick \& Grotpeter, 1995; Pagel, Erdly, \& Becker, 1987; Strough, Berg, \& Sansone, 1996; Walker, de Vries, \& Trevethan, 1987).

Although the existence of age and gender differences in the quantity, quality and relationship and individual outcomes of social interactions has, and continues to be explored in the literature, the specific mechanisms behind age and gender differences in frequency of interpersonal problems is not as well understood. Therefore, it was the 
specific aim of the current study to assess which factors may or may not be associated with age and gender differences in the frequency of experience of interpersonal problems.

\section{Research Questions and Hypotheses}

Research Question 1

Are there significant age differences in the experience of the frequency of interpersonal problems?

Preliminary Analyses; Hypothesis 1. Younger adults were expected to report a significantly lower frequency of experience of interpersonal problems.

Research Question 2

Are there significant gender differences in the experience of the frequency of interpersonal problems?

Preliminary Analyses; Hypothesis 2. Women were expected to report a significantly higher frequency of experience of interpersonal problems.

\section{Research Question 3}

Is there a main effect of age group on the linear combination of predictor variables (contact frequency, self-efficacy, positive, and negative relationship quality)?

Hypothesis 3. There will be a main effect of age group on the linear combination of predictor variables.

\section{Research Question 4}

Do each of four predictor variables (contact frequency, self-efficacy, positive, and negative relationship quality) differ by age group? 
Hypothesis 4. Older adults will report a lower frequency of contact with social partners than younger adults.

Hypothesis 5. Older adults will report a higher level of self-efficacy than younger adults.

Hypothesis 6. Older adults will report more positive relationship quality than younger adults.

Hypothesis 7. Older adults will report less negative relationship quality than younger adults.

Research Question 5

Which of four predictor variables (contact frequency, self-efficacy, positive, or negative relationship quality) serve as independent predictors of the frequency of experience of interpersonal problems?

Hypothesis 8 . Contact frequency will be positively associated with reported frequency of interpersonal problems.

Hypothesis 9. Self-efficacy will be inversely associated with reported frequency of interpersonal problems.

Hypothesis 10. Positive relationship quality will be inversely associated with reported frequency of interpersonal problems.

Hypothesis 11. Negative relationship quality will be positively associated with reported frequency of interpersonal problems. 


\section{Research Question 6.}

Do each of four predictor variables (contact frequency, self-efficacy, positive, and negative relationship quality) mediate the relationship between age and interpersonal problem frequency described in hypothesis 1 ?

Hypothesis 12. The age differences in reported contact frequency described in Hypothesis 4 will mediate the age difference in interpersonal problem frequency described in Hypothesis 1.

Hypothesis 13. The age differences in reported self-efficacy described in Hypothesis 5 will mediate the age difference in interpersonal problem frequency described in Hypothesis 1.

Hypothesis 14 . The age difference in positive relationship quality described in Hypotheses 6 will mediate the age difference in interpersonal problem frequency described in Hypothesis 1.

Hypothesis 15. The age difference in negative relationship quality described in Hypotheses 7 will mediate the age difference in interpersonal problem frequency described in Hypothesis 1.

Method

\section{Design}

The current study utilized archival cross-sectional data consisting of two age groups -younger and older adults (Strough, McFall, Flinn, \& Schuller, 2008)—to assess age and gender differences in the dependent variable: frequency of experience of interpersonal problems. The design of the current study included 4 predictor variables; contact frequency, self-efficacy, positive relationship quality, and negative relationship 
quality - each of which was tested as a potential mediator of age differences in the frequency of interpersonal problems.

\section{Participants}

Existing data from 78 college-aged younger adults $(18-27$ years, $M=19.47, S D=$ $1.36 ; 51.3 \%$ women, $92 \%$ never married, mean number of years of education $=13.63$ ) and 78 older adults living in the community $(58-91$ years, $M=74.15, S D=8.11,71.8 \%$ women, 33\% married, $44 \%$ widowed, $12 \%$ divorced, $1 \%$ never married) was used for the current study. Younger adult participants were recruited from student body at West Virginia University. Older adult participants were recruited from West Virginia and Pennsylvania through phone invitations, senior centers, and community groups. The original study (Strough et al., 2008) from which the data for the current study originated investigated dyadic collaboration, and so all participants were required to bring one same-sex friend who they had known for at least 6 months with them to the data collection session. Half of these pairs of friends collaborated (worked together) when completing the problem-solving tasks in the study, while the other half of the pairs of friends were separated, and worked alone while completing the problem-solving tasks. The interaction vs. no interaction condition was the only treatment difference between the groups. In the current study, only data from the participants who worked alone while completing the problem-solving tasks will be used, since there is only one data point for each dyad that completed the tasks together for some of the measures used in the current study. As compensation for their participation, each younger adult participant was given the option of receiving extra credit in their psychology class, or a $\$ 20$ honorariumchoice of extra credit or the honorarium was not related to any differences in performance 
(McFall, 2007). Each older adult participant was given a $\$ 20$ honorarium for their participation.

\section{Procedure}

Participants completed a variety of written self-report measures, however, only measures that were used for the current study will be discussed here. Participants completed a paper and pencil "Information About You" questionnaire, which included a measure of self-efficacy, an “Attitudes About Relationship Questionnaire” (AARQ), a "Relationship History Questionnaire" (RHQ), and an "Experience with Everyday Problems" questionnaire, which included a subset of problem vignettes from the Everyday Problem Solving Inventory (EPSI; Cornelius \& Caspi, 1987). The participants completed the measures at times and locations that were convenient for them. The majority of younger adults completed the measures in a meeting room in a laboratory in the Department of Psychology, while the majority of older adults completed the measures outside of the lab (mostly in meeting rooms at senior centers).

Informed consent was obtained from all participants before data collection.

Participants then completed the "Information About You" questionnaire before an experimenter provided the pairs of participants with a verbal description of the procedures of the study. Participants then completed the AARQ, RHQ, and "Experience With Everyday Problems" questionnaire alone in separate locations from their partner. 


\section{Measures}

\section{Demographics}

Participants completed a measure of several demographics variables on an "Information About You" questionnaire. These demographics variables included measures of age, race, and sex (See Appendix A).

\section{Contact Frequency}

Participants' frequency of contact with social partners was measured using three items which asked participants to report, on average, how many total hours they spent with the same-sex friend whom they had brought to the data collection session per week, on weekdays, and on weekends, respectively. The additive combination of the two items which asked how many total hours participants spent with their friends on weekdays and weekends, respectively, was theoretically redundant when compared to the item that asked participants how many hours they spent with their friends per week. However, the additive combination of these two items (total hours on weekdays and weekends) was, on average, significantly different than the single item regarding total hours per week. Analyses described below were initially conducted with both the single item (hours per week) and the combined two-item (total hours on weekdays and weekends) measures of contact frequency, but results did not differ. Thus, the results related to contact frequency described in this study are based on one item, which asked "On average, how many hours do you spend with your friend per week" $(M=17.80, S D=23.53$, range $=$ .50 to 96$)$. 


\section{Self-Efficacy}

Participants completed two self-efficacy scales adapted from Strough, Cheng, and Swenson (2002). The scale used in the current study (Appendix C) included nine items that asked participants to rate how their perceived abilities to solve different kinds of everyday problems had changed as they had aged. All items on the self-efficacy scale were global in the sense that they did not refer to participants' self-efficacy regarding their ability to solve problems with a specific person, but rather their ability to solve problems in general. For example, the scale included items such as the following: "As I have gotten older, my ability to solve interpersonal conflicts has:", to which participants selected a response from the following 3-point scale: "1 = Improved", "2 = Not changed", or "3 = Has declined". The self-efficacy variable for the current study was created by taking the average of the 9 self-efficacy items $(M=1.55, S D=.44$, range $=1$ to 3$)$. The nine items from this scale had good internal consistency $(\alpha=.89)$.

\section{Relationship Quality}

Participants completed a 20-item “Attitudes About Relationship Questionnaire” (AARQ; Appendix B), which included items adapted from Hall and Kierman (1992). Items included person-specific questions and statements about negative and positive aspects of the participants' relationship with the same-sex friend whom they had brought with them to the data collection session. Items included questions regarding the relationship such as "How much happiness do you get out of your relationship with your friend?", and statements such as "[my friend] Talks over his/her problems with me." Participants responded to the items on a 5-point numerical scale: 1(A Great Deal/Describes Very Much); 5 (None At All/Describes Not At All). 
The AARQ consisted of two scales_ — "Negative Friendship Quality" scale, and a “Positive Friendship Quality" scale. These two scales were identified by Keener and Strough (2007) through exploratory factor analysis using principal components extraction and a varimax rotation. The "Negative Friendship Quality" scale $(M=2.85, S D=1.48$, range $=1$ to $5, \alpha=.79)$, consisted of five items such as "[My friend] Argues back no matter what I say", whereas the "Positive Friendship Quality" scale $(M=2.74, S D=$ 1.20 , range $=1$ to $5, \alpha=.93)$, consisted of 15 items such as "[My friend] Respects my opinion". The factors representing positive and negative relationship quality did not correlate significantly $(r=.04)$ during factor analysis (Keener \& Strough). The nonsignificant correlation between these two factors underscores the fact that social interactions can involve both positive and negative outcomes (Berndt, 1996; Rook, 1984), and that these scales are measuring independent dimensions of the participants' social relationships. All items on the positive relationship quality scale were reverse-scored and then averaged to create a score for that scale so that a relationship with a greater degree of positive qualities was represented by a higher score. The negative relationship quality was scored in the same manner - a higher score on that scale also indicated a greater degree of negative relationship qualities.

Frequency of Interpersonal Everyday Problems

Participants completed an "Experience with Everyday Problems" questionnaire which included a subset of everyday problem vignettes taken from the Everyday Problem Solving Inventory (EPSI; Cornelius \& Caspi, 1987). Vignettes were selected on the basis that they described scenarios that both younger and older adults would have some experience with (Strough et al., 2008). Each vignette used in the present study described 
an interpersonal problem that participants may have experienced with any social partner, not necessarily the friend that participants had brought to the data collection session. Four vignettes were included in the current study. They are listed below.

Vignette \#1: "A friend criticizes you for an important decision you made."

Vignette \#2: "You are doing something you know perfectly well how to do by yourself, and a friend begins giving you advice you neither need nor want."

Vignette \#3: "You are with a group of people who begin gossiping about one of your friends."

Vignette \#4: “A person you used to be close to doesn't seem to care about you anymore."

The questionnaire included two items for each problem to assess participants' experience with the respective problem. The first item asked participants whether they had ever experienced each problem from each vignette, to which participants responded either "Yes" or "No". For those participants who answered "Yes", the second item asked participants to rate how often they had experienced that problem on a 7-point frequency scale: 1="Every few years", 2="At least once per year", 3="Every few months", 4="At least once a month", 5="Weekly", 6="Almost everyday", or 7="Everyday" (See appendix D).

Scoring: In the current study, for each problem, older and younger adults' responses to the two items were recoded so that each of the four dichotomous yes/no items were combined with each respective 7-point frequency scale to form four new 8point frequency scales with a value of "0" representing "no experience" with a given problem. More specifically, responses to each dichotomous " $y e s / n o$ " item which asked 
participants whether they had ever experienced a particular interpersonal problem were recoded so that a response of "no" would be represented as a " 0 " on the new 8-point frequency scale. All other values were the same as the original 7-point scale (a score of " 3 " on each of the original 7-point scales remained a score of " 3 " on each of the new 8point scales).

The dependent variable that was used for the current study - frequency of experience with interpersonal problems - was created by averaging the scores from the four new 8-point frequency scales $(M=2.04, S D=1.16$, range $=0$ to 4.75$)$. Higher scores indicated a greater frequency of experience with interpersonal everyday problems. The four items used to make this scale had good internal consistency $(\alpha=.70)$.

Results

\section{Data Screening}

Assumption of Independence. The assumption of independence was addressed using intraclass correlations prior to any analyses relevant to the research questions. Multiple significant intraclass correlations were observed (see Table 10), suggesting a violation of the assumption of independence. Ignoring non-independence results in analyses that are based on twice as many data points than they should be (Kenny, Kashy, \& Cook, 2006, chap. 2), which can essentially artificially inflate or deflate power, potentially increasing the likelihood of type one or type two errors, depending on the nature of the independent variable and the direction of its correlation with the dependent variable (Kenny, Kashy, \& Cook, p. 44-46). In order to address this concern, the data set was split in half to create two data sets, each of which contained the data from one participant from each of the dyads. This effectively controlled for the dependency in the 
data. Analyses were then conducted independently on each of these two halves of the data set and results from each of the two halves were compared to results obtained when using the entire data set. Results did not differ between either half of the split data set and the full data set. Thus, although the intraclass correlations suggested that the assumption of independence of observations in the full data set had been violated, this dependency did not bias the results. The results reported in the current study are based on data provided by person 1 from each dyad.

Missing Cases. Missing cases were found on items from each measurement scale representing each variable (contact frequency, self-efficacy, positive and negative relationship quality, and interpersonal problem frequency). Each measurement scale was comprised of a different numbers of items, and therefore a different total number of cases. The total number of cases missing for each measurement scale was calculated by summing the number of missing cases from each item on each measurement scale. Specifically, 7 of 156 (approx. 4\%) cases which comprised the contact frequency measurement scale were missing. Moreover, 46 of 780 (approx. 6\%) cases which comprised the negative relationship quality measurement scale were missing. Within the positive relationship quality measurement scale, 157 of 2340 (approx. 7\%) cases were missing. The self-efficacy measurement scale included 1404 cases, 66 (approx. 5\%) of which were missing. The 624 cases comprising the experience with interpersonal problems measurement scale included 32 (approx. 5\%) missing cases. In total, of the 5304 cases in the data set, 308 were missing (5.8\%). There were no missing cases for the age group variable. Datasets which are comprised of 5\% or fewer missing cases present relatively minor problems and the missing cases can be dealt with using a number of 
methods (Tabachnick, and Fidell, 2007). For the current study, all missing cases within a given item were substituted using the mean of that item for that particular age group (younger adults or older adults) (Tabachnick, and Fidell, 2007; Widaman, 2005).

Outliers. Several univariate outliers were found in the contact frequency variable within each age group. These outliers were identified using box plots and were well above the contact frequency variable mean within the group from which they originated. Outliers were recoded to be two standard deviations above each mean from each respective age group (Field, 2005, Tabachnick, and Fidell, 2007). No outliers were found for any of the other variables.

Normality: Each variable was assessed for normality by computing $z$-scores for skew and kurtosis. Of the five continuous variables assessed for normality, two variables - the self-efficacy and contact frequency variable — each exhibited significant positive skew $(z=2.89, p<.01, z=11.83, p<.001$, respectively). In larger samples, relatively minor deviations from normality will lead to values of skewness that are significant. Indeed, in samples of 200 or more, the fact that a given skewness value is statistically significant is somewhat arbitrary without knowledge of the absolute value of skewness and the shape of the distribution (Field, 2005; Tabachnick, and Fidell, 2007).

Given the relatively small degree of skewness, the shape of the distribution (which was close to normal), and the sample size, it was not deemed necessary to transform the self-efficacy variable. However, the degree of skew for the contact frequency variable was substantially greater in magnitude. In an effort to address the large degree of skew, a log transformation was conducted on the contact frequency variable, in accordance with the distribution of that particular variable (Tabachnick, and 
Fidell, 2007). The skew of the contact frequency variable was reduced, but still significant following the log transformation $(z=3.97, p<.001)$.

Analyses described in the following sections were originally performed with the transformed contact frequency variable, and also with the untransformed contact frequency variable - results were the same in terms of statistical significance. For ease of interpretation, the following sections refer to results obtained using the untransformed contact frequency variable.

Assumption of Homogeneity of Variances: Significant Levene's tests indicated that the variances of the two age groups were significantly different on the positive relationship quality, and contact frequency variables; $F(1,76)=4.22, p<.05, F(1,76)=$ $46.22, p<.001$, respectively. Field (2005) notes that in larger samples even small degrees of heterogeneity in group variances can produce significant Levene's tests, and that the assumption of homogeneity of variances can be double-checked using a variance ratio. Variance ratios above 2 suggest a violation of the assumption of homogeneity of variance - the variance ratio for the positive relationship quality variable was below 2 (1.68). The variance ratio for the contact frequency variable was much higher (40.09). Field suggests transforming variables when the assumption of homogeneity of variances cannot be met. However, as noted above, the contact frequency variable had been previously analyzed as a transformed variable due to significant skewness, and no differences had been found between analyses using the transformed and untransformed variable. Thus, it is reasonable to expect that the effects of these particular violations of the assumption of homogeneity of variances had a negligible degree of influence on the results reported in the current study. 


\section{Preliminary Analysis}

In order to address research questions 1 and 2 and determine whether there were age and/or gender differences in the frequency of experience of interpersonal problems, a 2 (gender: male, women) X 2 (age group: younger adult, older adult) factorial ANOVA was performed using interpersonal problem frequency as the dependent variable. The main effect of age group revealed that younger adults $(M=2.71, S D=.96)$ experienced significantly more interpersonal problems than older adults $(M=1.38, S D=.99) ; F(1$, $74)=31.01, p<.001, \eta_{p}^{2}=.23$. Thus, the preliminary analyses indicated that hypothesis 1 was supported—older adults reported that they experienced fewer interpersonal problems than younger adults (see Figure 1). No significant main effect of gender was observed, nor was there any significant age group $\mathrm{x}$ gender interaction $(p>.05)$, thus hypothesis 2 was not supported, and gender was not included in later analyses.

\section{Primary analyses}

MANOVA The third research question of whether there was an effect of age group on the linear combination of the four predictor variables (contact frequency, self-efficacy, positive, and negative relationship quality) was addressed using a multivariate analysis of variance (MANOVA). The MANOVA is less prone to Type 1 error in comparison to multiple univariate ANOVAs, but is also more difficult to interpret and may be prone to low power when intercorrelations of dependent variables are high (.60 and above) (Tabachnick \& Fidell, 2007). None of the dependent variables in this analysis had a positive correlation of .60 or higher (see Table 3), and the significant results reported below suggest that low power was not an issue in this analysis. Age group (younger, older adult) was a between-subjects variable, contact frequency, self-efficacy, and 
positive, and negative relationship quality were the dependent variables. A significant effect of age group was observed; $V(4,73)=.84, F(4,73)=95.76, p<.001, \eta_{p}^{2}=.84$ on the linear combination of dependent variables (see Table 1).

Planned simple comparisons were used to address research question 4, and revealed significant age differences in each of the four variables. Specifically, regarding contact frequency, younger adults reported significantly more frequent contact (number of hours per week) with the friend they brought with them to the testing situation than older adults; $F(1,76)=23.54, p<.001, \eta_{p}^{2}=.24$. Older adults reported significantly greater self-efficacy than younger adults; $F(1,76)=8.54, p<.001, \eta_{p}^{2}=.56$. Older adults also reported significantly higher levels of positive relationship quality than younger adults; $F(1,76)=100.11, p<.001, \eta_{p}^{2}=.57$. Similarly, older adults also reported significantly lower levels of negative relationship quality than younger adults; $F$ $(1,76)=245.36, p<.001, \eta_{p}^{2}=.76$. Thus, hypotheses $3,4,5,6$, and 7 were all supported (see Tables $1 \& 2$ ).

Regression To address the fifth research question of which of the four predictor variables (contact frequency, self-efficacy, positive relationship quality, or negative relationship quality) independently accounted for frequency of interpersonal problems, a hierarchical multiple linear regression was conducted. Based on previous research (Akiyama et al., 2003), contact frequency was entered in the first block of the regression analysis, and self-efficacy, positive relationship quality, and negative relationship quality were all entered in the second block. Interpersonal problem frequency was used as the criterion variable. 
Significant $(p<.001)$ correlations were observed between all predictor variables, however, no two predictors had strong enough correlations to indicate multicollinearity ( $R<.9$ for all correlations between predictors) (Tabachnick, and Fidell, 2007). All correlations between each predictor and interpersonal problem frequency were in the directions predicted by hypotheses $8,9,10$, and 11 were significant $(p<.01)$. Specifically, greater contact frequency $(R=.42)$ and greater negative relationship quality $(R=.52)$ were both associated with greater frequency of interpersonal problems. More positive relationship quality $(R=-.42)$ and greater self-efficacy $(R=-.45)$ were both associated with lesser average interpersonal problem frequency. Thus, hypotheses 8, 9, 10, and 11 were each supported (see Table 3).

Significant associations between the predictors and the criterion variable were observed in both the first model, which only included contact frequency as a predictor $\left[F_{\text {Model I }}(1,76)=16.05, p<.001\right]$, and in the second model, which included the remaining predictors $\left[F_{\text {Model } 2}(4,76)=9.41, p<.001\right]$. For the first model, an $R^{2}$ value of .17 was observed, indicating that contact frequency accounted for approximately $17 \%$ of the variability in interpersonal problem frequency. For the second model, an $R^{2}$ value of .34 was observed, indicating that the remaining predictor variables accounted for an additional $27 \%$ of the variability in the criterion variable - a significant change from the first model: $F_{\text {Change }}(3,73)=6.11, p<.01$. More specifically, greater contact frequency $(\beta=.25, p<.05)$ and greater negative relationship quality $(\beta=.39, p<.05)$ were both significantly associated with greater frequency of interpersonal problems. Self-efficacy and positive relationship quality were not observed to have significant relations with interpersonal problem frequency (see Table 4). The Durbin-Watson statistic was 2.41, 
thus indicating that the assumption that the errors in the regression are independent had been met (Field, 2005, p. 189).

Mediation Analyses The sixth research question - the question of whether the four predictor variables (contact frequency, self-efficacy, positive, or negative relationship quality) mediate the relationship between age and interpersonal problem frequency described in hypothesis 1 -was addressed using a series of regression analyses as described by Baron and Kenny (1986). In addition to testing for the necessary conditions set forth by Baron and Kenny, mediation was also assessed using a Sobel (1982) test to analyze whether each of the predictor variables significantly accounted for a reduction in the relation between age and interpersonal problem frequency.

There are several essential conditions that must be met in order for a variable to mediate the relation between a predictor and criterion variable. Specifically, (1) there must be a significant relation between the predictor (referred to here as $\mathrm{X}$ ) variable and the supposed mediator (referred to here as "M"), and (2) there must be a significant relation between the supposed mediator (M) and the criterion (referred to here as $\mathrm{Y}$ ) variable when the predictor (X) is controlled. Lastly, (3) a previously significant relation between the predictor $(\mathrm{X})$ and criterion $(\mathrm{Y})$ variables must become non-significant when the supposed mediator (M) is controlled (Barron \& Kenny, 1986; Preacher \& Hayes, 2004).

Using age group as the predictor $(\mathrm{X})$, and interpersonal problem frequency as the criterion $(\mathrm{Y})$, the preliminary condition for mediation was met for all mediation analyses; age group was significantly related to average interpersonal problem frequency $\left(\beta_{X Y}=-\right.$ $.57, p<.0001)$. Contact frequency, self-efficacy, positive, and negative relationship 
quality were each assessed independently as potential mediators (M). Each variable met the first essential condition needed for mediation; contact frequency, self-efficacy, positive relationship quality, and negative relationship quality were all significantly related to age group (X; $p<.0001)$. However, no variable met either the second or third essential condition for mediation (see Tables 5, 6, 7, and 8). Moreover, all Sobel tests were non-significant, further suggesting that the relation between age group (X) and interpersonal problem frequency $(\mathrm{Y})$ was not significantly reduced when any of the supposed mediators (M; contact frequency, self-efficacy, positive, or negative relationship) were included in the model. Thus, hypotheses $12,13,14$, and 15 were not supported (see Table 9).

\section{Discussion}

The current study assessed age differences in the frequency of experience of interpersonal problems, as well as several variables which were hypothesized to contribute to such age differences. The current study compliments the existing literature by showing findings consistent with those of previous researchers (Akiyama et al., 2003; Birditt, et al., 2005; Carstensen, 1992). Moreover, the current study further extends the existing literature by using measures of social relationship characteristics that included items that were more specific than the more broad and open-ended measures of social interactions used in previous studies (Akiyama et al.; Birditt, et al., Carstensen). Specifics regarding the findings and methodology of the current study are discussed below. 
Age Differences in Frequency of Experience of Interpersonal Problems

In support of hypothesis 1 (which predicted an inverse relation between age and interpersonal problem frequency), and similar to the findings of Akiyama and colleagues (2003), as well as those of Birditt and colleagues (2005), the current study suggests that older adults experience interpersonal problems at a lower frequency than younger adults. A reduced frequency of experience with interpersonal problems may be beneficial for older adults. Specifically, although interpersonal problems may be less common in older adulthood, when they do occur, they are not necessarily any less salient to older adults than younger adults in terms of their relation to negative outcomes such as depression (Finch \& Zautra, 1992; Pagel et al, 1987; Rook, 1984).

Moreover, the current study measured interpersonal problem frequency using items that included very specific examples of interpersonal problems. Previous research regarding age differences in exposure to interpersonal problems, on the other hand, has either relied on diary data (Birditt, et al., 2005), interview data (Birditt \& Fingerman, 2003), or measures that did not assess the occurrence of specific types of interpersonal problems (Akiyama, et al., 2003). Individuals of different ages may interpret open-ended interview questions differently (Schwartz, 1999), and non-specific measures of interpersonal tensions may assess other constructs, such as relationship quality, as much as they do frequency of experience of interpersonal problems. Therefore, the current study's assessment of the frequency of experience of interpersonal problems offers a greater degree of precision than the measures used in previous research. 
Gender Differences in the Frequency of Experience of Interpersonal

Problems

The current study helps to clarify previously ambiguous findings regarding gender differences in the frequency of interpersonal problems. Previous research has revealed gender differences in how individuals interpret and react to interpersonal problems (Birditt \& Fingerman, 2003; Strough, et al., 1996), but findings regarding gender differences in the frequency of experience of interpersonal problems have been inconsistent. However, the current study shows a lack of gender differences in the frequency of experience of interpersonal problems - thus underscoring the importance of differentiating between gender differences in how individuals experience interpersonal problems, and how often they experience them. For instance, previous research has found women to be more likely to emphasize interpersonal aspects of problems (Strough et al., 1996; Walker et al., 1987), and report more distress when facing interpersonal problems (Birditt \& Fingerman, 2003) than men — thus adding to our understanding of gender differences in how individuals experience such problems.

On the other hand, with the exception of some studies (Crick \& Grotpeter, 1995; Krause \& Shaw, 2002; Stephens et al., 1987) that drew from specific populations (i.e., adolescents, stroke victims, disabled individuals), surprisingly little research has assessed gender differences in the frequency of experience with interpersonal problems. Thus, relatively little is known regarding gender differences in how often adults experience interpersonal problems in the general population; the current study helps to add to this under-investigated area of the 
literature. Specifically, the current study suggests that despite previously observed gender differences in how interpersonal problems are experienced (Birditt \& Fingerman, 2003; Strough et al., 1996; Walker et al., 1987), there may be no consistent gender differences in how often interpersonal problems are experienced.

The method of sample selection and the fact that all participants were required to bring a friend who they had known for at least 6 months to the data collection session may also be related to the lack of gender differences in experience with interpersonal problems. In particular, it may be that the older adult men in the current study were not representative of the general population in the sense that they may have had more social relationships than other men of their age, as evidenced by their involvement in long-term friendships. Previous research (Antonucci, Akiyama, \& Lansford, 1998) has shown that older adult men often have smaller social networks than older adult women, and that older adult women tend to rely on multiple social partners for support, while older adult men seek support mostly from their spouses (Antonucci \& Akiyama, 1987). If the men in the current study were not representative of the larger population of men, the findings might indicate that when men and women have social networks that are relatively more similar, they are equally likely to experience interpersonal problems.

Age Differences in Contact Frequency and Positive Relationship Quality

The current study adds further credence to Akiyama and colleagues' findings and to Socioemotional Selectivity Theory (Carstensen, 1992; Lang \& Carstensen, 2002) by showing that as individuals age, their frequency of contact with social partners decreases, while perceived positive relationship qualities generally increase. Thus, the results of the current study support hypotheses 4 and 
6 , which predicted that in comparison to younger adults, older adults would report less frequent social contact and a greater degree of positive relationship quality, respectively.

It is important to note that although contact frequency with social partners declines in older adulthood, the perceived importance of positive relationship quality does not diminish; older adults place as much value on positive, mutuallybeneficial social relationships as younger adults (Hartup \& Stevens, 1997). Moreover, Hartup and Stevens note that in terms of fostering positive developmental outcomes, relationship quality may be more important than the existence of the relationship itself. That is, whether one has a good or bad relationship may have greater implications than simply whether one has a relationship or not. Indeed, others (Roberto \& Scott, 1986) have noted the importance of relationship quality factors such as perceived equity with regard to outcomes such as individuals' satisfaction with their friends. Thus, the reduced contact that older adults reported experiencing in the current study may be of less consequence to various outcomes with friends such as the interpersonal problems, given the greater degree of positive relationship quality that the older adults reported experiencing in comparison to the younger adults.

With regard to methodology, some previous studies have used relationship quality measures which were relatively broad in nature (Akiyama et al., 2003), or have relied on interview data to obtain information regarding age changes in positive relationship qualities such as emotional closeness (Carstensen, 1992). The measure of positive relationship quality in the current study, however, utilized 
specific examples of behaviors that characterize positive relationship qualities.

Thus, the findings do not necessarily suggest an age effect on participants' broad perceptions of their relationships, but rather on specific instances of positive interactions within the participants' relationships; aspects of the relationship that Hartup and Stevens refer to as the "surface structure" of the relationship (1997; p. 356).

\section{Age Differences in Self-Efficacy}

The current study clarifies the nature of the relations between self-efficacy and age. Although previous research has been somewhat less clear regarding age differences in self-efficacy (Lachman, 1986) the current study suggests that, in support of hypotheses 5 (which predicted a positive relation between age and selfefficacy), older adults report higher self-efficacy than younger adults. These findings extend previous research showing positive relations between self-efficacy and effective performance in social contexts (Caprara, et al., 2003; Christie \& Segrin, 1998; Hopf \& Colby, 1992), as well as findings highlighting older adults' increased self-efficacy and problem-solving abilities in ecologically relevant domains such as interpersonal relations (Artistico, et al., 2003).

It is important to note, however, that although the measure of self-efficacy used in the current study did include one item specifically related to self-efficacy when dealing with interpersonal problems, the rest of the items in the measure referred to a variety of other types of problems. Furthermore, the measure of selfefficacy in the current study included items referring to behaviors which were relatively broad in scope (e.g. making everyday judgments), but also included items 
that explicitly described more specific behaviors (e.g. solving interpersonal problems). Thus, the results of the current study are more strongly indicative of an age difference in general self-efficacy, rather than self-efficacy specifically related to dealing with interpersonal problems.

Age Differences in Negative Relationship Quality

The current study suggests that older adults experience fewer negative relationship qualities than younger adults. Thus, hypothesis 7 , which predicted an inverse relation between age and negative relationship quality, was supported. The potentially beneficial implications of older adults' ability to avoid interactions marked by negative relationship qualities should not be underestimated, given the poor outcomes associated with negative social exchanges (Finch \& Zautra, 1992; Pagel et al, 1987; Rook, 1984).

Furthermore, the measure of negative relationship quality used in the current study utilized items that included specific examples of behavioral interactions that characterize negative relationship quality. Previous studies (Akiyama et al., 2003) have used measures which were not only less specific, but included fewer items, and subsequently had a lower degree of reliability $(\alpha=.53)$ than the measure of negative relationship quality used in the current study, which had better reliability $(\alpha=.79)$. Therefore, the current study adds to the existing literature by employing a measure of negative relationship quality that not only included more specific examples of negative relationship quality, but also assessed a more comprehensive range of specific negative relationship qualities, and was more reliable than previously used measures. 


\section{Mediation Analyses}

The current study suggests that neither contact frequency, self-efficacy, positive relationship quality, or negative relationship quality mediates the inverse relation between age and frequency of experience of interpersonal problems. This may be the first study to examine whether these variables act as mediators of the inverse relation between age and frequency of experience of interpersonal problems. Therefore, the results of the mediation analyses in the current study should be replicated in future research.

However, it is important to note that each variable met the first criteria for mediation (Baron \& Kenny, 1986), in that each was associated with the IV (age group), thus further emphasizing the age differences in individuals' self-efficacy and the characteristics of their social interactions. Furthermore, each variable was significantly associated with interpersonal problem frequency in the directions predicted by hypotheses $8,9,10$, and 11 . Specifically, negative relationship quality and contact frequency were both positively related to interpersonal problem frequency, while self-efficacy and positive relationship quality were both inversely related to interpersonal problem frequency. However, these associations were no longer significant in the third step of each mediation analyses, where the dependent variable (interpersonal problem frequency) was regressed on both the independent variable (age group), and the supposed mediator variables (Baron \& Kenny).

It may be that there are other variables that were not measured in the current study that better account for the inverse relation between age and frequency of experience of interpersonal problems. For instance, previous research has suggested that older adults 
may be more skilled at dealing with interpersonal problems. In particular, Strough and colleagues (2008) have shown that older adults may be less likely to endorse the use of interpersonal problem-solving strategies that involve self-assertion than younger adults, and that older adults are more effective at interpersonal problem-solving when working in a dyad than younger adults. Other researchers have also noted evidence suggesting that older adults may select more effective interpersonal problem-solving strategies than younger adults (Blanchard-Fields et al., 2007). Thus, interpersonal problem-solving strategy effectiveness may be a potential mediator of the inverse relation between age and interpersonal problem frequency.

It is also possible that although contact frequency, self-efficacy, positive, and negative relationship qualities are all related to interpersonal problem frequency when including data from both age groups, these relations diminish in significance when considering only one age group at a time. Indeed, other research (Schlosnagle \& Strough, 2008) using the same data set that the current study utilized has shown that these relations do reduce in significance when assessing one age group independently of the other.

\section{Specificity of Measures}

The current study adds to the existing body of literature by taking a direct and specific approach to measuring the frequency of experience of interpersonal problems, self-efficacy, and positive and negative relationship quality. For instance, when comparing two items used to measure positive relationship qualityone item from the current study's measure, and one from the measure employed by Akiyama and colleagues (2003) — it is possible to see how the items in the current 
study are more specific. The item used in Akiyama and colleagues' measure reads "I feel my (e.g. mother) supports me, that she is there when I need her" (p. 72), whereas a comparable item from the current study's measure of positive relationship quality reads "(my friend) praises me and the things I do". The item from the current study's measure describes a specific and concrete example of social behavior that characterizes positive relationship quality, whereas the item in Akiyama and colleagues' measure is broader. Thus, the current study helps to lend support to the notion that there are age differences in how often individuals experience explicitly described types of interpersonal problems, how they experience self-efficacy when considering specific examples of everyday problems, and how their social relationships are characterized by specific examples of positive and negative qualities. Moreover, despite the specificity of its measures, the current study presents results that converge with those of previous research which used broader measures, or open-ended diary or interview data (Akiyama, et al., Artistico, et al., 2003; 2003; Birditt, et al., 2005; Carstensen, 1992; Lang \& Carstensen, 2002). This suggests that these are findings that can be reliably replicated across different methodologies.

A particularly interesting aspect of the current study can be observed when considering the way in which the measures in the current study were worded. Specifically, the measures of positive and negative relationship quality, as well as the measure of contact frequency were person-specific in that they referred to the same-sex friend that participants had brought with them to the data collection site. However, the measures of self-efficacy and interpersonal problem frequency were 
not person-specific. Nevertheless, there were significant associations between measures that were person-specific and those that were not, such as the significant associations between all of the person-specific measures (contact frequency, positive and negative relationship quality) and the measure of frequency of experience of interpersonal problems. This suggests that even very specific aspects of the participants' social lives, such as their negative relationship quality with one specific friend, were related to more global social issues, such as their general frequency of experience with interpersonal problems.

\section{Effect Sizes}

The sizes of the effects of age group on interpersonal problem frequency, contact frequency, self-efficacy, positive, and negative relationship quality are all large by Cohen's (1988) standards. Thus, a large degree of variation in each of these variables can be attributed to age group (Field, 2005). This is particularly interesting for the self-efficacy and positive relationship quality variables, since the relation between each of these and age has been somewhat uncertain in the past (Akiyama et al., 2003; Lachman, 1986).

It is possible that the large effect sizes of age on self-efficacy, positive and negative relationship quality, and interpersonal problem frequency may be partly due to the very specific way in which each variable was measured. If this is the case, the current study contributes to the existing literature by illustrating the importance of gaining precision in measurement by using measures which include items involving explicitly described examples of the behaviors that researchers are attempting to assess. Moreover, these effect sizes call attention to the robust relation that age has with self-efficacy, social 
contact frequency, and the quality of relationships that individuals maintain with social partners.

\section{Limitations}

There are several limitations of the current study that could explain why neither contact frequency, self-efficacy, positive relationship quality, or negative relationship quality acted as mediators. Specifically, the inconsistencies in the types of social relationships each measure referred to could have influenced the effects of variables which were expected to act as mediators of the association between age group and interpersonal problem frequency. For instance, the contact frequency variable, which was person-specific, may have acted as a mediator if the measure of interpersonal problem frequency had also been person-specific

However, it is important to note that even self-efficacy, which was consistent with the measure of interpersonal problem frequency in that it was measured in a global, nonperson-specific fashion, did not act as a mediator. Moreover, the correlations presented in Table 3 undermine the argument that the lack of support for hypotheses 12 through 15 was caused entirely by the fact that the wording of some measures were person-specific while others were global.

In addition to the limitations which may have been implicated in the lack of mediation, there are several other limitations of the current study that should be noted. First is the fact that the DV, frequency of experience of interpersonal problems, was assessed using a measure that included only four items. Although the internal consistency of this measure was good $(\alpha=.70)$, a measure with more items may have gleaned a more comprehensive assessment of the participants' frequency of experience 
with interpersonal problems. The use of other methods, such as open-ended responses or structured interviews, in conjunction with the measure used in the current study, may have also provided a more in-depth assessment of the participants' experience with interpersonal problems.

Furthermore, it is possible that the age differences in reported experience with interpersonal problems was not necessarily due to actual age differences in frequency of experience with such problems, but was instead due to an age difference in interpretations of, and reactions to the measure — an issue of measurement equivalence (Baltes, Reese, \& Nesselroade, 1988). Older adults may interpret or respond differently to descriptions of negative events than younger adults; indeed, recent research has suggested age-related decreases in reactivity to negative information (Kisley, Wood, \& Burrows, 2007). Indeed, although negative information tends to elicit a stronger response than positive information in terms of brain activity, this "negativity bias" has been shown to be less prevalent in older adults than younger adults (Wood \& Kisley, 2006).

Another potential limitation of the current study is the way in which participants were selected. Specifically, because of the nature of the study, all participants were required to have at least one friend who they had known for at least 6 months (Strough et al., 2008). Therefore, all participants were selected partly based on their ability to maintain at least one friendship, which may have resulted in a sample of participants that had better than average social skills. Moreover, the average duration of friendships differed between age groups; older adults reported knowing their friends for longer than the younger adults (Strough et al., 2008). Thus, the age differences in the person-specific measures such as positive and negative relationship quality may have been a product of 
the duration of the relationship, rather than age alone. Additionally, if the duration of older adults' relationships with the friends they brought to the data collection session was any indication, their friendships in general may have been of a longer duration than those of younger adults, which could have contributed to the observed age differences in frequency of experience with interpersonal problems. Nevertheless, it should be noted that both younger and older adults were required to bring a friend who they had known for at least 6 months with them to the data collection session (Strough, et al., 2008).

Lastly, and of concern to the general interpretation of the findings of the current study, is the fact that because the sample was cross-sectional, age and cohort are confounded. Because of this, no inferences can be made regarding change in behavior across time - rather the findings can only be interpreted as age differences (Baltes, Reese, \& Nesselroade, 1988).

\section{Implications and Future Directions}

In terms of the potential implications of the current study, the findings suggest that older adults may be more adept at navigating the challenges of social interaction than younger adults. Future research should be aimed at clarifying specifically what mechanisms account for the inverse relation between age and frequency of experience of interpersonal problems. Some researchers have already taken a step in this direction by studying age differences in individuals' emotional and behavioral reactions to interpersonal problems (Birditt \& Fingerman, 2003; Birditt, et al., 2005) and in individuals' approaches to solving emotionally salient problems - such as interpersonal problems (Blanchard-Fields, et al., 1995; Blanchard-Fields, et al., 2007; Blanchard- 
Fields, et al., 2004). Such research may have implications for interventions designed to facilitate adaptive methods of managing interpersonal conflict.

Despite the lack of any mediating qualities of the variables in the current study, there may be other variables that act as mediators of the inverse association between age and frequency of experience of interpersonal problems. Other researchers have suggested age differences in individuals' emotional reactions to (Birditt, et al., 2005) and strategies of dealing with (Blanchard-Fields, et al., 2007; Strough et al., 2008) interpersonal problems. Such variables could theoretically act as mediators of the relation between age and frequency of experience with interpersonal problems observed in the current study, and should be studied in future research.

\section{Conclusions}

Social interactions are a relevant aspect of both younger and older adults' everyday lives, although they are characterized by age differences in positive and negative qualities, degree of self-efficacy, contact frequency, and frequency of experience of interpersonal problems. In general, although they experience a reduced degree of social contact, older adults tend to experience greater self-efficacy than younger adults, and have social interactions characterized by more positive relationship qualities, fewer negative relationship qualities, and fewer interpersonal problems than younger adults. Self-efficacy and positive relationship quality are both inversely related to frequency of experience of interpersonal problems, whereas contact frequency and negative relationship quality are both positively related to the frequency of experience of interpersonal problems. However, none of the variables in the current study have been 
shown to mediate the inverse association between age and frequency of experience of interpersonal problems. 


\section{References}

Akiyama, H., Antonucci, T., Takahashi, K., \& Langfahl, E. S. (2003). Negative interactions in close relationships across the life span. Journal of Gerentology, $58 B, 70-79$.

Antonucci, T. C. \& Akiyama, H. (1987). An examination of sex differences in social support among older men and women. Sex Roles, 17, 737-749.

Antonucci, T. C., Akiyama, H., \& Lansford, J. E. (1998). Negative effects of close social relations. Family Relations, 47, 379-384.

Artistico, D., Cervone, D., \& Pezzuti, L. (2003). Percieved self-efficacy and everyday problem solving among young and older adults. Psychology and Aging, 18, 6879.

Baltes, P. B. (1997). On the incomplete architecture of human ontogeny: Selection, optimization, and compensation as foundation of developmental theory. American Psychologist, 52, 366-380.

Baltes, P. B., Reese, H. W., \& Nesselroade, J. R. (1988). Life-span developmental psychology: Introduction to research methods. Hillsdale, NJ: Lawrence Erlbaum Associates, Inc.

Bandura, A. (1986). Social foundations of thought and action: A social cognitive theory. Englewood Cliffs, NJ: Prentice-Hall.

Bandura, A., Adams, N. E., \& Beyer, J. (1977). Cognitive processes mediating behavioral change. Journal of Personality and Social Psychology, 35,125-139. 
Bandura, A., \& Cervone, D. (1983). Self-evaluative and self-efficacy mechanisms governing the motivational effects of goal systems. Journal of Personality and Social Psychology, 45, 1017-1028.

Bandura, A., Cioffi, D., Taylor, B. C., \& Brouillard, M. E. (1988). Perceived selfefficacy in coping with cognitive stressors and opioid activation. Journal of Personality and Social Psychology, 55, 479-488.

Bandura, A., Reese, L., \& Adams, N. E. (1982). Microanalysis of action and fear arousal as a function of differential levels of perceived self-efficacy. Journal of Personality and Social Psychology, 43, 5-21

Baron, R. M., \& Kenny, D. A. (1986). The moderator-mediator variable distinction in social psychological research: Conceptual, strategic, and statistical considerations. Journal of Personality and Social Psychology, 51, 1173-1182.

Berg, C. A., Strough, J., Calderone, K. S., Sansone, C., \& Weir, C. (1998). The role of problem definitions in understanding age and context effects on strategies for solving everyday problems. Psychology and Aging, 13, 29-44.

Berndt, T. J. (1996). Exploring the effects of friendship quality on social development. In W. M. Bukowski, A. F. Newcomb, \& W. W. Hartup (Eds.), The company they keep: Friendship in childhood and adolescence. New York, NY: Cambridge University Press.

Berndt, T. J. (2002). Friendship quality and social development. Current Directions in Psychological Science, 11, 7-10. 
Birditt, K. S., \& Fingerman, K. L. (2003). Age and gender differences in adults' descriptions of emotional reactions to interpersonal problems. Journal of Gerontology: Psychological Sciences, 58B, 237-245.

Birditt, K. S., Fingerman, K. L., \& Almeida, D. M. (2005). Age differences in exposure and reactions to interpersonal tensions: A daily diary study. Psychology and Aging, 20, 330-340.

Blanchard-Fields, F., Jahnke, H. C., \& Camp, C. (1995). Age differences in problemsolving style: The role of emotional salience. Psychology and Aging, 10, 173180.

Blanchard-Fields, F., Mienaltowski, A., \& Seay, R. B. (2007). Age differences in everyday problem-solving effectiveness: Older adults select more effective strategies for interpersonal problems. Journal of Gerontology: PSYCHOLOGICAL SCIENCES, 62 B, 61-64.

Blanchard-Fields, F., Stein, R., \& Watson, T. L. (2004). Age differences in emotionregulation strategies in handling everyday problems. Journal of Gerontology: PSYCHOLOGICAL SCIENCES, 59, 261-269.

Blieszner, R., \& Adams, R. G. (1998). Problems with friends in old age. Journal of Aging Studies, 12, 223-239.

Carstensen, L. L. (1992). Social and emotional patterns in adulthood: Support for socioemotional selectivity theory. Psychology and aging, 7, 331-338.

Carstensen, L. L., Isaacowitz, D. M., \& Charles, S. T. (1999). Taking time seriously a theory of socioemotional selectivity. American Psychologist, 54, 165-181. 
Carstensen, L. L., Pasupathi, M., Mayr, U., \& Nesselroade, J. R. (2000). Emotional experience in everyday life across the adult life span. Journal of Personality and Social Psychology, 79, 644-655.

Caprara, G. V., Steca, P., Cervone, D., \& Artistico, D. (2003). The contribution of selfefficacy beliefs to dispositional shyness: On social-cognitive systems and the development of personality dispositions. Journal of Personality, 71, 943-970.

Christie, V., \& Sergin, C. (1998). The influence of self-efficacy and of gender on the performance of social and nonsocial tasks. Journal of Applied Communication Research, 26, 374-389.

Cohen, J. (1998). Statistical power analysis for the behavioral sciences $\left(2^{\text {nd }}\right.$ ed.). Mahwah, NJ: Lawrence Erlbaum Associates

Cornelius, S. W., \& Caspi, A. (1987). Everyday problem solving in adulthood and old age. Psychology and Aging, 2, 144-153.

Crick, N. R., \& Grotpeter, J. K. (1995). Relational aggression, gender, and socialpsychological adjustment. Child Development, 66, 710-722.

Field, A. (2005). Discovering statistics using SPSS for windows: (and sex, drugs, and rock 'n' roll), $\left(2^{\text {nd }} e d\right)$. Thousand Oaks, CA: Sage Publications.

Finch, J. F. \& Zautra, A. J. (1992). Testing latent longitudinal models of social ties and depression among the elderly: A comparison of distribution-free and maximum likelihood estimates with nonnormal data. Psychology and Aging, 7, 107-118.

Fredrickson, B. L., \& Carstensen, L. L. (1990). Choosing social partners: How old age and anticipated endings make people more selective. Psychology and Aging, 5, $335-347$. 
Hall, L.A., \& Kiernan, B.S. (1992). Psychometric assessment of a measure of the quality of primary intimate relationships. Health Values: The Journal of Health Behavior, Education \& Promotion, 16, 30-39.

Hartup, W. W., (1996). The company they keep: Friendships and their developmental significance. Child Development, 67, 1-13.

Hartup, W. W., \& Stevens, N. (1997). Friendship and adaptation in the life course. Psychological Bulletin, 121, 355-370.

Hopf, T., \& Colby, N. (1992). The relationship between interpersonal communication apprehension and self-efficacy. Communication Research Reports, 9, 131-135.

Horowitz, A., Reinhardt, J. P., Boerner, K, \& Travis, L. A. (2003). The influence of health, social support quality and rehabilitation on depression among disabled elders. Aging \& Mental Health, 7, 342-350.

Keener, E., \& Strough, J. (2007). Friendship quality: Do age and gender matter? Poster session presented at the meeting of the Gerontological Society of America, San Francisco, CA.

Kenny, D. A., Kashy, D. A., \& Cook, W. L. (2006). Dyadic data analysis. New York, NY: The Guilford Press.

Kisley, M. A., Wood, S., \& Burrows, C. L. (2007). Looking at the sunny side of life: Age-related change in an event-related potential measure of the negativity bias. Psychological Science, 18, 838-843.

Krause, N., \& Shaw, B. A. (2002). Negative interaction and changes in functional disability during late life. Journal of Social and Personal Relationships, 19, 339359. 
Lachman, M. E. (1986). Personal control in later life: Stability, change, and cognitive correlates. In M. M. Baltes \& P. B. Baltes (Eds.), The psychology of control and aging (pp. 207-236). Hillsdale, NJ: Lawrence Erlbaum Associates, Inc.

Lang, F. R., \& Carstensen, L. L. (1994). Close emotional relationships in late life: Further support for proactive aging in the social domain. Psychology and Aging, 9, 315-324.

Lang, F. R., \& Carstensen, L. L. (2002). Time counts: Future time perspective, goals, and social relationships. Psychology and Aging, 17, 125-139.

Matsushima, R., \& Shiomi, K. (2003). Social self-efficacy and interpersonal stress in adolescence. Social Behavior and Personality, 31, 323-332.

McFall, J. P. (2007). Examining the effectiveness of older and younger adults' strategies for solving interpersonal and individual everyday problems. Unpublished master's thesis, West Virginia University, Morgantown.

Oswald, D. L., Clark, E. M., \& Kelly, C. M. (2004). Friendship maintenance: An analysis of individual and dyad behaviors. Journal of Social and Clinical Psychology, 23, 413-441.

Pagel, M. D., Erdly, W. W., \& Becker, J. (1987). Social networks: We get by with (and in spite of) a little help from our friends. Journal of Personality and Social Psychology, 53, 793-804.

Polletta, F., \& Jasper, J. M. (2001). Collective identity and social movements. Annual Review of Sociology, 27, 283-305. 
Preacher, K. J., \& Hayes, A. F. (2004). SPSS and SAS procedures for estimating indirect effects in simple mediation models. Behavior Research Methods, Instruments, \& Computers, 36, 717-731.

Roberto, K. A., \& Scott, J. P. (1986). Friendships of older men and women: Exchange patterns and satisfaction. Psychology and Aging, 1, 103-109.

Rook, K. S. (1984). The negative side of social interaction: Impact on psychological well-being. Journal of Personality and Social Psychology, 46, 1097-1108.

Sansone, B. \& Berg, C. A. (1993). Adapting to the environment across the life span: Different process or different inputs? International Journal of Behavioral Development,16, 215-241.

Schlosnagle, L., \& Strough, J. (2008, November). Age Differences in Younger and Older Adults' Experience of Interpersonal Problems. Poster session presented at the $61^{\text {st }}$ Annual Scientific Meeting of the Gerontological Society of America, National Harbor, MD.

Schwartz, N. (1999). Self-reports. How the questions shape the answers. American Psychologist, 54, 93-105.

Sobel, M. E. (1982). Asymptotic confidence intervals for indirect effects in structural equation models. In S. Leinhart (Ed.), Sociological methodology 1982 (pp. 290312. San Francisco: Jossey-Bass.

Sorkin, D. H., \& Rook, K. S. (2006). Dealing with negative social exchanges in later life: Coping responses, goals, and effectiveness. Psychology and Aging, 21, 715-725. 
Staudinger, U. M., \& Baltes, P. B. (1996). Interactive minds: A facilitative setting for wisdom-related performance? Journal of Personality and Social Psychology, 71, 746-762.

Stephens, M. A. P., Kinney, J. M., Norris, V. K., \& Ritchie, S. W. (1987). Social networks as assets and liabilities in recovery from stroke by geriatric patients. Psychology and Aging, 2, 125-129.

Strough, J., Berg, C. A., \& Sansone, C. (1996). Goals for solving everyday problems across the life span: Age and gender differences in the salience of interpersonal concerns. Developmental Psychology, 32, 1106-1115.

Strough, J., Cheng, S., \& Swenson, L. M. (2002). Preferences for collaborative and individual everyday problem solving in alter adulthood. International Journal of Behavior Development, 26, 26-35.

Strough, J., McFall, J. P., Flinn, J. A., \& Schuller, K. L. (2008). Collaborative everyday problem solving among same-gender friends in early and later adulthood. Psychology and Aging, 23, 517-530.

Tabachnick, B. G. \& Fidell, L. S. (2007). Using multivariate statistics ( $5^{\text {th }}$ ed.). Boston: Pearson.

Walker, L. J., de Vries, B., \& Trevethan, S. D. (1987). Moral stages and moral orientations in real-life and hypothetical dilemmas. Child Development, 58, 842858.

Widaman, K. F. (2005). Missing data: What to do with or without them. In Monographs of the Society for Research in Child Development, 71 (3, Serial No. 285). 
Wong, M. M., \& Csikszentmihalyi, M. (1991). Affiliation motivation and daily experience: Some issues on gender differences. Journal of Personality and Social Psychology, 60, 154-164.

Wood, S., \& Kisley, M. A. (2006). The negativity bias is eliminated in older adults: Agerelated reduction in event-related brain potentials associated with evaluative categorization. Psychology and Aging, 21, 815-820. 
Table 1

Multivariate and Univariate Analysis of Variance of the Effect of Age Group on Contact Frequency, Self-Efficacy, Positive, and Negative Relationship Quality

\begin{tabular}{|c|c|c|c|c|c|}
\hline & & \multicolumn{4}{|c|}{ Univariate } \\
\hline & & Contact & Self- & Positive & Negative \\
\hline & $\underline{\text { Multivariate }}$ & Frequency & Efficacy & Rel. Qual. & Rel. Qual. \\
\hline Source & $\underline{F}(4,73)$ & $\underline{F}(1,76)$ & $\underline{F}(1,76)$ & $\underline{F}(1,76)$ & $\underline{F}(1,76)$ \\
\hline Age Group & $95.76^{*}$ & $23.54^{*}$ & $106.93 *$ & $100.11 *$ & $245.36^{*}$ \\
\hline
\end{tabular}

Note: Multivariate F statistics are generated from Pallai's Trace statistic.

$* p<.001$ 
Table 2

Mean Scores and Standard Deviations for Measures of Contact Frequency, Self-Efficacy, Positive, and Negative Relationship Quality for as a Function of Age Group

\begin{tabular}{|c|c|c|c|c|}
\hline \multirow[b]{3}{*}{ Measure } & \multicolumn{4}{|c|}{ Age Group } \\
\hline & \multicolumn{2}{|c|}{ Older Adults } & \multicolumn{2}{|c|}{$\underline{\text { Younger Adults }}$} \\
\hline & $\mathrm{M}$ & $\mathrm{SD}$ & $\mathrm{M}$ & $\mathrm{SD}$ \\
\hline Contact Frequency & $6.10_{\mathrm{a}}$ & 4.67 & $29.36_{a}$ & 29.57 \\
\hline Self-Efficacy & $1.89_{\mathrm{b}}$ & .32 & $1.24_{b}$ & .24 \\
\hline Positive Rel. Qual. & $3.62_{\mathrm{c}}$ & .88 & $1.84_{\mathrm{c}}$ & .67 \\
\hline Negative Rel. Qual. & $1.53_{\mathrm{d}}$ & .71 & $4.15_{\mathrm{d}}$ & .77 \\
\hline
\end{tabular}

$\underline{\text { Note. Means in a row sharing a subscript are significantly different }(p<.001)}$ 
Table 3

Correlation Coefficients for Relations Among Contact Frequency, Self-Efficacy, Positive, and Negative Relationship Quality, and Average Interpersonal Problem Frequency

\begin{tabular}{|c|c|c|c|c|c|}
\hline & 1. Contact & 2. Self- & 3. Positive & 4. Negative & 5 Internersonal \\
\hline Measure & Frequency & Efficacy & Rel. Qual. & Rel. Qual. & Prob. Freq. \\
\hline 1. & - & $-.41 *$ & $-.35 *$ & $.52 *$ & $.42 *$ \\
\hline 2. & & - & $.61 *$ & $-.67 *$ & $-.45 *$ \\
\hline 3. & & & - & $-.79 *$ & $-.42 *$ \\
\hline 4. & & & & - & $.52 *$ \\
\hline 5. & & & & & - \\
\hline
\end{tabular}

${ }^{*} p<.01$ 
Table 4

Hierarchical Regression for Variables Predicting Average Interpersonal Problem Frequency

\begin{tabular}{lllll}
\hline Variable & $B$ & $S E B$ & $\beta$ \\
\end{tabular}

Step 1
Contact Frequency
.02
.005
$.42 *$

Step 2

$\begin{array}{lccc}\text { Contact Frequency } & .01 & .005 & .25^{*} \\ \text { Self-Efficacy } & -.29 & .36 & -.12 \\ \text { Positive Relationship Quality } & .04 & .16 & .04 \\ \text { Negative Relationship Quality } & .31 & .13 & .39^{*}\end{array}$

Note. $R^{2}=.17, F(1,76)=16.05, p<.001$ for Step $1 ; \Delta R^{2}=.17, \mathrm{p}<.001$ for Step 2

$* \mathrm{p}<.001$ 
Table 5

Contact Frequency as a Mediator of the Relation Between Age Group and Average

Interpersonal Problem Frequency

\begin{tabular}{llrrr} 
Requirement no. & Variable & $B$ & $S E B$ & $\beta$ \\
\hline 1 & Age Group_-Interpersonal Prob. Freq. & -1.33 & .22 & $-.57^{*}$ \\
$2 \mathrm{a}$ & Age Group_Contact Freq. & -23.26 & 4.79 & $-.47^{*}$ \\
$2 \mathrm{~b}$ & Contact Freq.-Interpersonal Prob. Freq. ${ }^{\mathrm{a}}$ & .01 & .01 & .12 \\
3 & Age Group.-Interpersonal Prob. Freq. ${ }^{\mathrm{b}}$ & -1.12 & .25 & $-.48^{*}$ \\
& & & & \\
\hline
\end{tabular}

${ }^{\mathrm{a}}$ Controlling for age group. ${ }^{\mathrm{b}}$ Controlling for contact freq. ${ }^{*} p<.00001$ 
Table 6

Self-Efficacy as a Mediator of the Relation Between Age Group and Average

Interpersonal Problem Frequency

\begin{tabular}{llrrr} 
Requirement no. & Variable & $B$ & $S E B$ & $\beta$ \\
\hline 1 & Age Group_-Interpersonal Prob. Freq. & -1.33 & .22 & $-.57^{*}$ \\
$2 \mathrm{a}$ & Age Group_-Self-Efficacy & .66 & .06 & $.77^{*}$ \\
$2 \mathrm{~b}$ & Self-Efficacy_-Interpersonal Prob. Freq. ${ }^{\mathrm{a}}$ & -.10 & .39 & -.04 \\
3 & Age Group.-Interpersonal Prob. Freq. ${ }^{\mathrm{b}}$ & -1.26 & .34 & $-.54^{*}$ \\
& & & & \\
\hline
\end{tabular}

${ }^{\mathrm{a} C}$ Controlling for age group. ${ }^{\mathrm{b}}$ Controlling for self-efficacy. ${ }^{*} p<.00001$ 
Table 7

Positive Relationship Quality as a Mediator of the Relation Between Age Group and Average Interpersonal Problem Frequency

\begin{tabular}{|c|c|c|c|c|}
\hline Requirement no. & Variable & $B$ & $S E B$ & $\beta$ \\
\hline 1 & Age Group-Interpersonal Prob. Freq. & -1.33 & .22 & $-.57 *$ \\
\hline $2 \mathrm{a}$ & Age Group_-Pos. Rel. Qual. & 1.77 & .18 & $-.75^{*}$ \\
\hline $2 b$ & Pos. Rel. Qual.-Interpersonal Prob. Freq. ${ }^{\text {a }}$ & .01 & .14 & .02 \\
\hline 3 & Age Group.-Interpersonal Prob. Freq. ${ }^{\mathrm{b}}$ & -1.35 & .34 & $-.58^{*}$ \\
\hline
\end{tabular}

${ }^{\mathrm{a} C}$ Controlling for age group. ${ }^{\mathrm{b}}$ Controlling for positive relationship quality. ${ }^{*} p<.00001$ 
Table 8

Negative Relationship Quality as a Mediator of the Relation Between Age Group and Average Interpersonal Problem Frequency

\begin{tabular}{llrrr} 
Requirement no. & Variable & $B$ & $S E B$ & $\beta$ \\
\hline 1 & Age Group_Interpersonal Prob. Freq. & -1.33 & .22 & $-.57^{*}$ \\
$2 \mathrm{a}$ & Age Group_Neg. Rel. Qual. & -2.63 & .17 & $-.87^{*}$ \\
$2 \mathrm{~b}$ & Neg. Rel. Qual._-Interpersonal Prob. Freq. ${ }^{\mathrm{a}}$ & .09 & .15 & .11 \\
3 & Age Group.-Interpersonal Prob. Freq. & -1.09 & .46 & $-.47^{*}$ \\
& & & & \\
\end{tabular}

${ }^{\mathrm{a}}$ Controlling for age group. ${ }^{\mathrm{b}}$ Controlling for negative relationship quality. ${ }^{*} p<.00001$ 
Table 9

Significance of Indirect Effect of Age Group on Interpersonal Problem Frequency

Through Each Potential Mediator (Sobel Test)

\begin{tabular}{lcccc}
\hline & & & \multicolumn{2}{c}{$95 \%$ CI } \\
\cline { 3 - 4 } & & & Lower & Upper \\
Path & & & Limit & Limit \\
\hline Age Group_Interpersonal Prob. ${ }^{\mathrm{a}}$ & -.21 & .22 & -.47 & .05 \\
Age Group_Interpersonal Prob. ${ }^{\mathrm{b}}$ & -.07 & .26 & -.59 & .45 \\
Age Group_Interpersonal Prob. ${ }^{\mathrm{c}}$ & .02 & .26 & -.47 & .53 \\
Age Group_Interpersonal Prob. ${ }^{\mathrm{d}}$ & -.23 & .39 & -1.01 & .55 \\
\hline
\end{tabular}

${ }^{a}$ Through contact frequency. ${ }^{\mathrm{b}}$ Through self-efficacy. ${ }^{\mathrm{c}}$ Through positive relationship quality. ${ }^{\mathrm{d}}$ Through negative relationship quality. 
Table 10

Intraclass Correlation Coefficients Between All Variables

\begin{tabular}{llllll}
\hline & Contact & Self- & Positive & Negative & Interpersonal \\
Measure & Frequency 1 & Efficacy 1 & Rel. Qual.1 & Rel. Qual. 1 & Prob. Freq. 1 \\
& & & & & \\
\hline Contact & $.96^{* *}$ & & & \\
Frequency 2 & & & &
\end{tabular}

Self-

$.52^{* *}$

Efficacy 2

Positive

$.83^{* *}$

Rel. Qual. 2

Negative

$.85^{* *}$

Rel. Qual. 2

Interpersonal

$.22 *$

Prob. Freq. 2

${ }^{* *} p<.001,{ }^{*} p<.05$ 


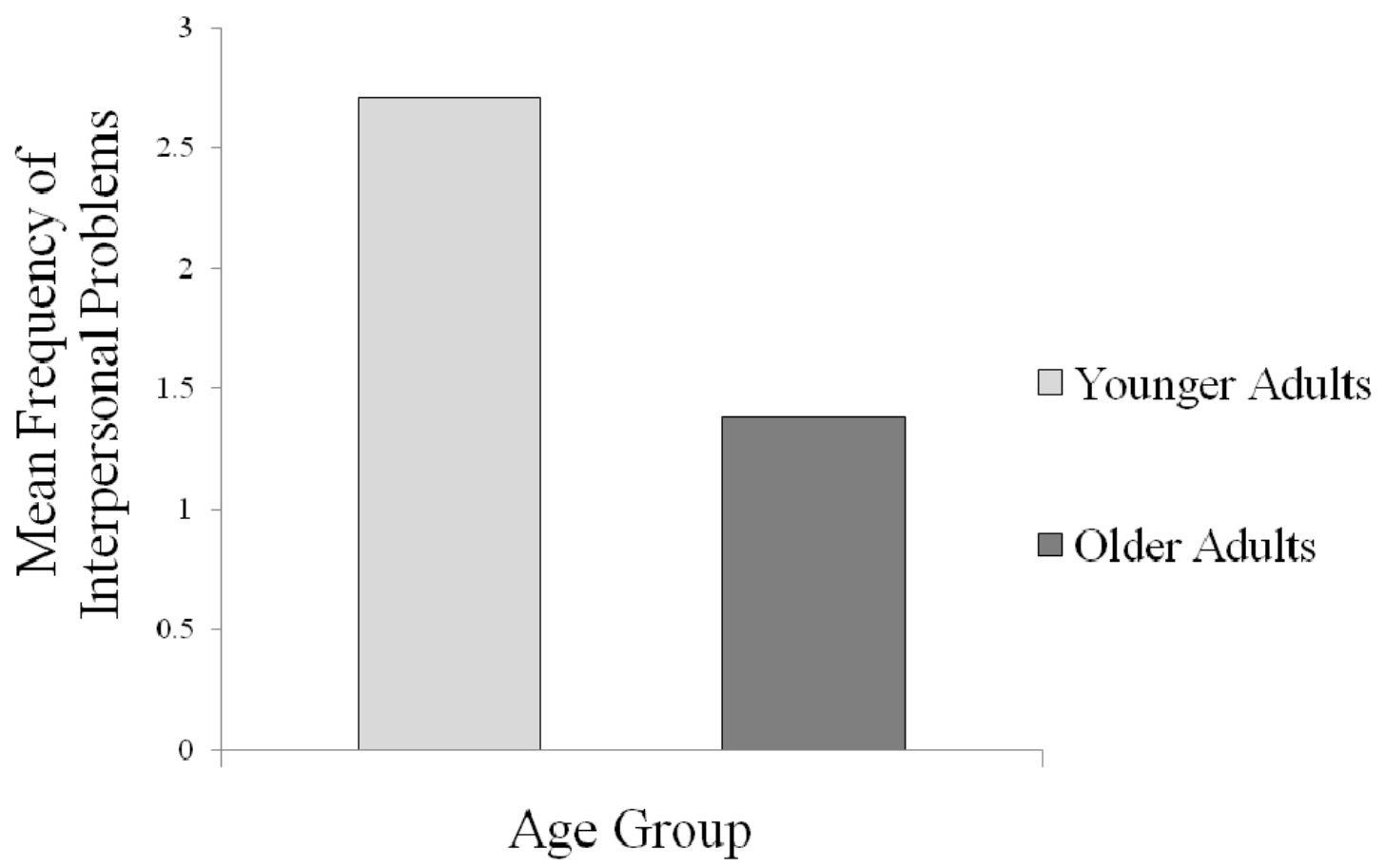

Figure 1. Average interpersonal problem frequency score among younger and older adults ( $0=$ "No experience with interpersonal problems", 1="Every few years", 2="At least once per year", 3="Every few months", 4="At least once a month", 5="Weekly", 6="Almost everyday", or 7="Everyday") 


\section{Appendix A}

\section{Demographics Questionnaire}

- Sex: $\square$ Male $\square$ Female (check one)

- Age: in years

- Date of Birth: (Month/Day/Year)

- Race (check one): $\square$ African American

$\square$ Asian

$\square$ Caucasian

$\square$ Hispanic

$\square$ Biracial (Specify):

$\square$ Other (Specify):

- Number of years of education: in years

(Examples: High school degree $=12$ years; two years of college $=14$ years; four years of college $=16$ years)

- Highest Degree Earned:

(Examples: High school diploma, associates, bachelors, masters, doctoral)

- What is your marital status?

(Check one \& please specify number of years).

$\square$ Married for yrs. \& mo.

Not married, but living together for yrs. \& yrs \& widowed for yrs. \& and divorced for yrs.

Divorced, married for yrs.

Never married

Other (specify:

Estimation of the yearly income you (and members of your household if you share expenses) received last year from all sources. Include wages, social security, pensions, annuities, interest, etc:

less than 10,000

$50,000-59,000$

$10,000-19,900$ $60,000-69,000$

$20,000-29,000$ 70,000 or more

$30,000-39,000$ I do not know/don't wish to answer $40,000-49,000$ 
Do you currently live: (Check one)

$\square$ Alone
$\square$ With a spouse
$\square$ With a significant other (boyfriend/girlfriend)
$\square$ With a friend who is not related to me
$\square$ With relatives (specify relationship:
$\square$ With others (specify relationship_

What kind of work have you done most of your life? (specify):

For what kind of business, company or agency is that? (specify):

What is your current work status? Are you:

$\square$ Employed full time
$\square$ Employed part time
$\square$ Retired
$\square$ Unemployed
$\square$ Homemaker
$\square$ Other (specify

What kind of work does/did your mother do?

What kind of work does/did your father do?

What kind of work does/did your spouse do?

- Number of siblings: (living and deceased)

- Number of children: (living and deceased)

- What city/town and state are you a permanent resident of? city/town state:

For the items below, please place a check mark next to the item that best describes you.

How would you rate your overall health at the present time?

$\square$ Excellent
$\square$ Good
$\square$ Fair
$\square$ Poor


Is your health now better, about the same, or not as good as it was 3 years ago?

$\square$ Better

$\square$ Same

$\square$ Not as good

Do your health problems stand in the way of your doing the things you want to do?

$\square$ Not at all

$\square$ A little

$\square$ A great deal

Compared with most other people your age, would you say your health is:

$\square$ Better,

$\square$ The Same

$\square$ Not as good?

Compared with most people your age, would you say your memory is:

$\square$ Better,

$\square$ The Same

$\square$ Not as good? 


\section{Appendix B}

\section{Attitudes About Relationship Questionnaire}

Instructions: Read the questions below. Circle the response that best represents your feelings, attitudes, and opinions. Be honest. Your responses are private. In the questions below, "friend" refers to the person you came with to today's session.

1. How much happiness do you get out of your life in general?
1 A great deal
2 Some
3 Neutral
4 Little
5 None at all

2. How much happiness do you get out of your relationship with your friend?
1 A great deal
2 Some
3 Neutral
4 Little
5 None at all

3. How much happiness do you think your friend gets out of his or her life in general?
1 A great deal
2 Some
3 Neutral 4 Little
5 None at all

4. How much happiness do you think your friend gets out of the relationship with you?
1 A great deal
2 Some
3 Neutral 4 Little
5 None at all

Please carefully read the statements below and indicate, on average, how much the statement describes your friend.

Because not all friendships are alike, some of the questions may not fit your relationship with your friend. If this is the case, select the response that indicates "describes not at all."

Other statements may fit your relationship very well. In these cases, select the response that indicates "describes very much."

5. Talks over his/her problems with me.

\begin{tabular}{|c|c|c|c|}
\hline $\begin{array}{l}1 \text { Describes } \\
\text { very much }\end{array}$ & $\begin{array}{l}2 \text { Describes } \\
\text { much }\end{array}$ & 3 Undecided & $\begin{array}{l}4 \text { Describes } \\
\text { little }\end{array}$ \\
\hline
\end{tabular}

6. Is always trying to change me.

$\begin{aligned} & 1 \text { Describes } \\ & \text { very much }\end{aligned}$
$\begin{gathered}\text { Describes } \\ \text { much }\end{gathered}$$\quad \begin{gathered}\text { Undecided } \\ 4 \text { Describes } \\ \text { little }\end{gathered} \quad \begin{gathered}5 \text { Describes not } \\ \text { at all }\end{gathered}$

7. Respects my opinion.

\begin{tabular}{|c|c|c|}
\hline $\begin{array}{l}\text { Describes } \\
\text { ery much }\end{array}$ & $\begin{array}{l}2 \text { Describes } \\
\text { much }\end{array}$ & 3 Undecided \\
\hline
\end{tabular}


8. Often tells me he/she loves me.

\begin{tabular}{|c|c|c|c|}
\hline $\begin{array}{l}1 \text { Describes } \\
\text { very much }\end{array}$ & $\begin{array}{l}2 \text { Describes } \\
\text { much }\end{array}$ & 3 Undecided & $\begin{array}{l}4 \text { Describes } \\
\text { little }\end{array}$ \\
\hline
\end{tabular}

9. Knows when to back off and let me be.

\begin{tabular}{|c|c|c|}
\hline $\begin{array}{l}1 \text { Describes } \\
\text { very much }\end{array}$ & $\begin{array}{l}2 \text { Describes } \\
\text { much }\end{array}$ & 3 Undecided \\
\hline
\end{tabular}

10. Tries to understand how I see things.

\begin{tabular}{|c|c|c|c|}
\hline $\begin{array}{l}1 \text { Describes } \\
\text { very much }\end{array}$ & $\begin{array}{l}2 \text { Describes } \\
\text { much }\end{array}$ & 3 Undecided & $\begin{array}{l}\text { 4 Describes } \\
\text { little }\end{array}$ \\
\hline
\end{tabular}

11. Argues back no matter what I say

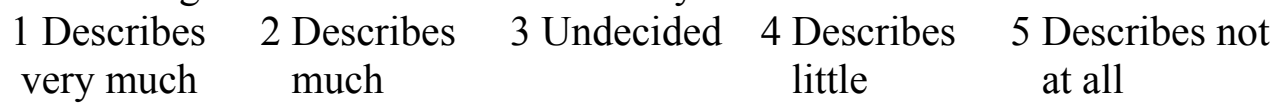

12. Wants to have the last word on how we spend our time.

\begin{tabular}{|c|c|c|c|}
\hline $\begin{array}{l}1 \text { Describes } \\
\text { very much }\end{array}$ & $\begin{array}{l}2 \text { Describes } \\
\text { much }\end{array}$ & ided & $\begin{array}{l}\text { 4 Describes } \\
\text { little }\end{array}$ \\
\hline
\end{tabular}

13. Lets me make up my own mind.

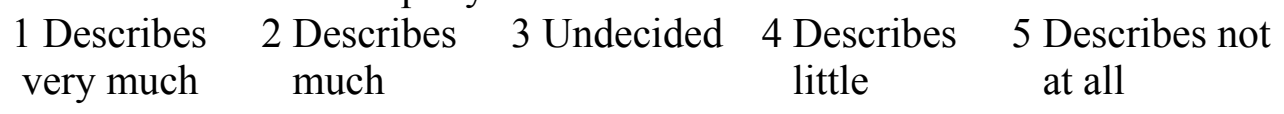

14. Respects my need to be alone at times.

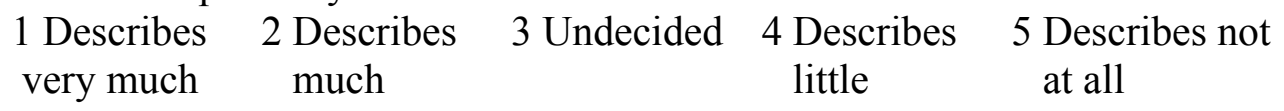

15. Is happy to go along with my decisions.

\begin{tabular}{|c|c|c|}
\hline $\begin{array}{l}1 \text { Describes } \\
\text { very much }\end{array}$ & $\begin{array}{l}2 \text { Describes } \\
\text { much }\end{array}$ & 3 Undecided \\
\hline
\end{tabular}

16. Expects me to do everything his/her way.

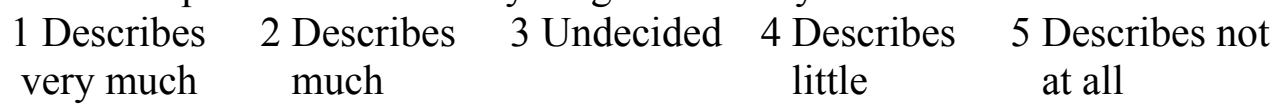

17. Thinks it's ok if I disagree with him/her

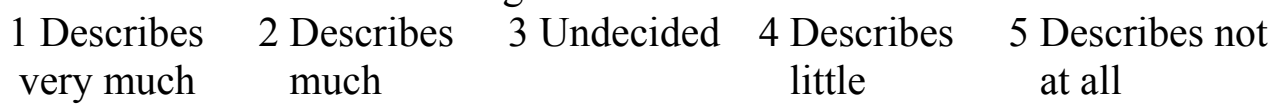

18. Thinks I'm worth listening to.

\begin{tabular}{|c|c|c|c|}
\hline $\begin{array}{l}1 \text { Describes } \\
\text { very much }\end{array}$ & $\begin{array}{l}2 \text { Describes } \\
\text { much }\end{array}$ & ided & $\begin{array}{l}4 \text { Describes } \\
\text { little }\end{array}$ \\
\hline
\end{tabular}


19. Tells me I'm attractive.

\begin{tabular}{|c|c|c|c|}
\hline $\begin{array}{l}1 \text { Describes } \\
\text { very much }\end{array}$ & $\begin{array}{l}2 \text { Describes } \\
\text { much }\end{array}$ & 3 Undecided & $\begin{array}{l}4 \text { Describes } \\
\text { little }\end{array}$ \\
\hline
\end{tabular}

$20 . \quad$ Considers my point of view.

1 Describes 2 Describes 3 Undecided 4 Describes 5 Describes not very much much little at all

21. Praises me and the things I do.

1 Describes 2 Describes 3 Undecided 4 Describes 5 Describes not very much much little at all

22. Respects my need for time for myself.

1 Describes 2 Describes 3 Undecided 4 Describes 5 Describes not very much much little at all

23. Gives me as much freedom as I want.

1 Describes 2 Describes 3 Undecided 4 Describes 5 Describes not very much much little at all

24. Provides emotional support.

1 Describes 2 Describes 3 Undecided 4 Describes 5 Describes not very much much little at all

25. Often irritates or annoys me.

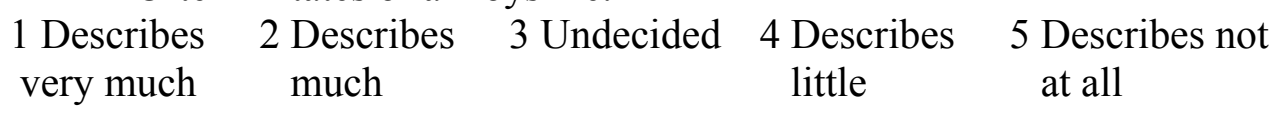

26. Is trustworthy.

1 Describes 2 Describes 3 Undecided 4 Describes 5 Describes not very much much little at all

27. How happy are you in this relationship?
1 Very
2 Somewhat 3 Neutral
4 Little
5 Not at all

28. How happy do you think your friend is in this relationship?
1 Very
2 Somewhat 3 Neutral
4 Little
5 Not at all 


\section{Appendix C}

Self-Efficacy Scale: Change in Perceived Ability Over the Past Several Years

\section{Please answer the following items about how you view your ability to deal with everyday problems. Circle one alternative for each question.}

\section{As I have gotten older, my ability to:}

a. solve everyday problems has:

b. solve interpersonal conflicts has:

c. solve everyday problems with housework and managing a household has:

d. make everyday decisions and judgments everyday problems has:

e. solve everyday problems with my health has:

f. solve everyday problems dealing with my memory has:

g. solve everyday problems dealing with preparing meals has:

h. solve everyday problems dealing with medications has:

i. solve everyday problems dealing with finances has:
This ability has Improved

Improved

Improved

Improved

Improved

Improved

Improved

Improved

Improved

Improved
This ability has Not Changed

Not Changed

Declined ability has Declined

Declined

Declined Changed

\section{Not}

Declined Changed

Not Declined
Changed

Not

Declined Changed

Not

Declined Changed

Not Declined
Changed

Not

Declined Changed

Not

Declined 
Appendix D

Your Experience with Everyday Problems

The following questions deal with your experience with the situations described on the previous pages.

1. You have let your home become too cluttered with items you use infrequently but which have much sentimental value for you.

a. Have you ever faced a problem similar to the one described above?

Circle one: YES NO

b. If YES, how often have you faced this problem?

\begin{tabular}{|c|c|c|c|c|c|}
\hline $\begin{array}{l}1 \text { Every } \\
\text { Few } \\
\text { Years }\end{array}$ & $\begin{array}{l}2 \text { At least } \\
\text { once per } \\
\text { year }\end{array}$ & $\begin{array}{l}3 \text { Every few } \\
\text { months }\end{array}$ & $\begin{array}{l}4 \text { At least } \\
\text { once a } \\
\text { month }\end{array}$ & 5 Weekly & $\begin{array}{l}6 \text { Almost } \\
\text { everyday }\end{array}$ \\
\hline
\end{tabular}

2. A friend criticizes you for an important decision you made.

a. Have you ever faced a problem similar to the one described above?

Circle one: YES NO

b. If YES, how often have you faced this problem?

$\begin{array}{lllllll}\text { 1 Every } & 2 \text { At least } & 3 \text { Every few } & 4 \text { At least } & 5 \text { Weekly } & 6 \text { Almost } & 7 \text { Everyday } \\ \text { Few } & \text { once per } & \text { months } & \begin{array}{l}\text { once a } \\ \text { month }\end{array} & & \text { everyday } & \\ \text { Years } & \text { year } & & & & \end{array}$

3. Because of a lack of time you have let household chores begin to pile up.

a. Have you ever faced a problem similar to the one described above?

Circle one: YES NO

b. If YES, how often have you faced this problem?

$\begin{array}{lllllll}\text { 1 Every } & 2 \text { At least } & 3 \text { Every few } & 4 \text { At least } & 5 \text { Weekly } & 6 \text { Almost } & 7 \text { Everyday } \\ \text { Few } & \text { once per } & \text { months } & \begin{array}{l}\text { once a } \\ \text { month }\end{array} & & \text { everyday } & \\ \text { Years } & \text { year } & & & & \end{array}$


4. You are doing something you know perfectly well how to do by yourself, and a friend begins giving you advice you neither need nor want.

a. Have you ever faced a problem similar to the one described above?

Circle one: YES NO

b. If YES, how often have you faced this problem?

$\begin{array}{lllllll}\text { 1 Every } & 2 \text { At least } & 3 \text { Every few } & 4 \text { At least } & 5 \text { Weekly } & 6 \text { Almost } & 7 \text { Everyday } \\ \text { Few } & \text { once per } & \text { months } & \begin{array}{l}\text { once a } \\ \text { month }\end{array} & & \text { everyday } & \\ \text { Years } & \text { year } & & & & \end{array}$

5. You are with a group of people who begin gossiping about one of your friends.

a. Have you ever faced a problem similar to the one described above?

Circle one: YES NO

b. If YES, how often have you faced this problem?

$\begin{array}{lllllll}\text { 1 Every } & 2 \text { At least } & 3 \text { Every few } & 4 \text { At least } & 5 \text { Weekly } & 6 \text { Almost } & 7 \text { Everyday } \\ \text { Few } & \text { once per } & \text { months } & \begin{array}{l}\text { once a } \\ \text { month }\end{array} & & \text { everyday } & \\ \text { Years } & \text { year } & & & & \end{array}$

6. You have a limited income. You don't have enough money to pay your bills.

a. Have you ever faced a problem similar to the one described above?

Circle one: YES NO

b. If YES, how often have you faced this problem?

$\begin{array}{lllllll}\text { 1 Every } & 2 \text { At least } & 3 \text { Every few } & \begin{array}{l}4 \text { At least } \\ \text { once a } \\ \text { Few }\end{array} & 5 \text { Weekly } & 6 \text { Almost } & 7 \text { Everyday } \\ \text { Years } & \text { year } & \text { months } & \begin{array}{l}\text { month } \\ \text { everyday }\end{array} & \end{array}$


7. A person you used to be close to doesn't seem to care about you anymore.

a. Have you ever faced a problem similar to the one described above?

$$
\text { Circle one: YES NO }
$$

b. If YES, how often have you faced this problem?

\begin{tabular}{|c|c|c|c|c|c|}
\hline $\begin{array}{l}\text { Every } \\
\text { Few } \\
\text { Years }\end{array}$ & $\begin{array}{l}2 \text { At least } \\
\text { once per } \\
\text { year }\end{array}$ & $\begin{array}{l}3 \text { Every few } \\
\text { months }\end{array}$ & $\begin{array}{l}4 \text { At least } \\
\text { once a } \\
\text { month }\end{array}$ & 5 Weekly & $\begin{array}{l}6 \text { Almost } \\
\text { everyday }\end{array}$ \\
\hline
\end{tabular}

